\title{
Scalable Synthesis of Ultrasmall Metal Oxide Radio-Enhancers Outperforming Gold
}

\author{
Lukas R.H. Gerken, Anna L. Neuer, Pascal M. Gschwend, Kerda Keevend, Alexander Gogos, \\ Alexandre H.C. Anthis, Leonie Aengenheister, Sotiris E. Pratsinis, Ludwig Plasswilm, \\ and Inge K. Herrmann*
}

Cite This: Chem. Mater. 2021, 33, 3098-3112

Read Online

ACCESS | Lلll Metrics \& More | 回 Article Recommendations | SI Supporting Information

\begin{abstract}
Nanoparticle-based radio-enhancement has the potential to improve cancer cell eradication by augmenting the photoelectric cross-section of targeted cancer cells relative to the healthy surroundings. Encouraging results have been reported for various nanomaterials, including gold and hafnia. However, the lack of scalable synthesis methods and comparative studies is prohibitive to rationalized material design and hampers translation of this promising cancer management strategy. Here, we present a scalable $\left(>100 \mathrm{~g} \mathrm{day}^{-1}\right)$ and sterile alternative to conventional batch synthesis of group IV metal oxides $\left(\mathrm{TiO}_{2}, \mathrm{ZrO}_{2}\right.$, and $\left.\mathrm{HfO}_{2}\right)$, which yields near-

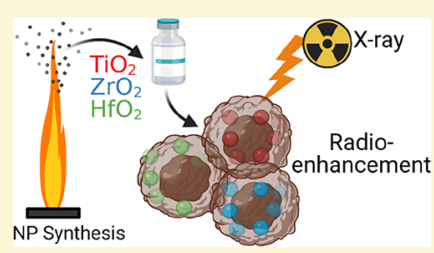
monodisperse ultrasmall metal oxide nanoparticles with radio-enhancement properties. Access to group IV oxide nanoparticles, which solely differ in atomic number but otherwise exhibit comparable morphologies, sizes, and surface chemistries, enables the direct comparison of their radio-enhancement properties to rationally guide material selection for optimal radio-enhancement performance. We show that the metal oxide nanoparticles exhibit atomic-number-dependent radio-enhancement in cancer cells (HT1080 and HeLa), which is attenuated to baseline levels in normal fibroblasts (normal human dermal fibroblasts). The observed radio-enhancement effects show excellent agreement with physical dose enhancement and nanoparticle dosimetry calculations. Direct benchmarking against gold nanoparticles, the current gold standard in the field, rationalizes the use of hafnia nanoparticles based on their radio-enhancement performance, which is superior to equi-sized gold nanoparticles. Taken together, the competitive radio-enhancement properties for near-monodisperse nanoparticles produced by scalable and sterile flame spray synthesis offer a route to overcoming key roadblocks in the translation of nanoparticle-based radio-enhancers.
\end{abstract}

$\mathrm{R}$ adiation therapy is an integral component in the management of patients affected by cancer. Due to the associated short- and long-term damage caused by ionizing radiation, the maximum radiation dose that can safely be applied is limited. ${ }^{1}$ One of the main challenges of radiation therapy is the delivery of an effective dose that can eradicate the tumor while sparing the surrounding normal tissue. ${ }^{2}$

Most commonly, external high-energy beams are targeted to the location of the tumor and deposit energy in the tissue while passing through. ${ }^{3}$ To achieve the highest possible loco-regional control of the dose with lower toxicities, advanced treatment modes using intensity-modulated beams and complex beam arrangements have been developed. ${ }^{4}$ Compared with conventional, uniform beam-based radiotherapy, intensity-modulated radiotherapy is more prone to marginal misses and is associated with increased "beam-on" times, ${ }^{1}$ total body exposure and radiation scattering, and leakage that might cause secondary malignancies. ${ }^{4} \mathrm{New}$ strategies are needed to mitigate such radiation-induced negative side effects and to further optimize the effectiveness of radiotherapy. ${ }^{3}$ In this context, modifications that allow the application of lower radiation doses for eradication of cancerous cells are particularly sought after.

Tissue-specific application of substances with radio-sensitizing properties that enhance the therapeutic window and outcome of radiotherapy is a highly appealing strategy. ${ }^{3,5}$ The radio-sensitization properties of small molecule chemotherapeutic drugs such as cisplatin have been harnessed in the clinic for decades, ${ }^{6}$ but their inherent cytotoxicity requires careful dose adjustment and limits the therapeutic window. ${ }^{6}$ Concurrent chemo-radiotherapy using traditional and new generation drugs could be leveraged to enhance the sensitivity of cancer cells to radiation while displaying non-overlapping toxicities. ${ }^{7}$ Alternatively, nanoparticles consisting of elements with high atomic number $(Z)$ have been used to increase the $\mathrm{X}$-ray absorption cross section of tumor tissues compared with their healthy surroundings. ${ }^{8}$ For photon energies $(E)$ at which the photoelectric effect is dominant, the absorption cross section scales approximately with $\mathrm{Z}^{4} \mathrm{E}^{-3}$, building a physical rationale for the use of high- $Z$ nanoparticles. ${ }^{9}$ Interestingly,

Received: November 27, 2020

Revised: March 24, 2021

Published: April 23, 2021 
A) WetChem Synthesis (batch)

WetChem

FSP
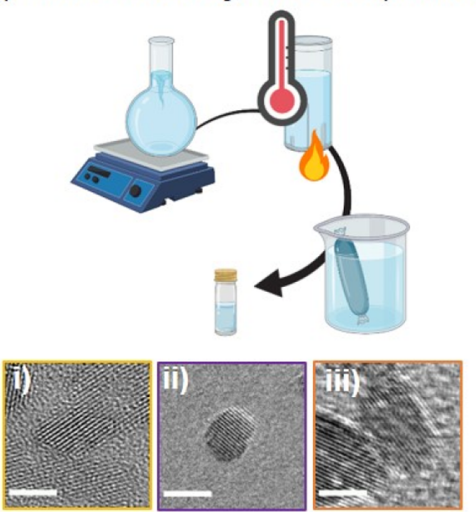

B) FSP (continuous)

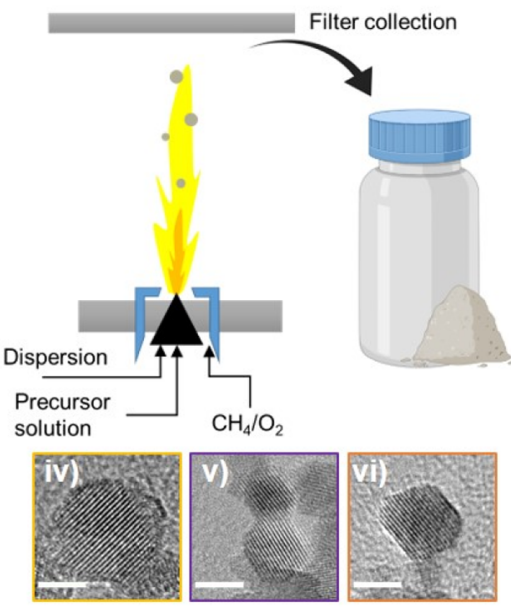

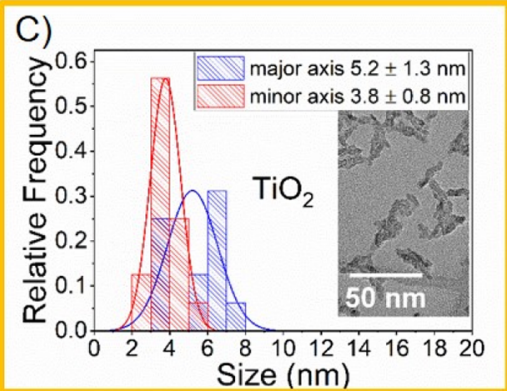
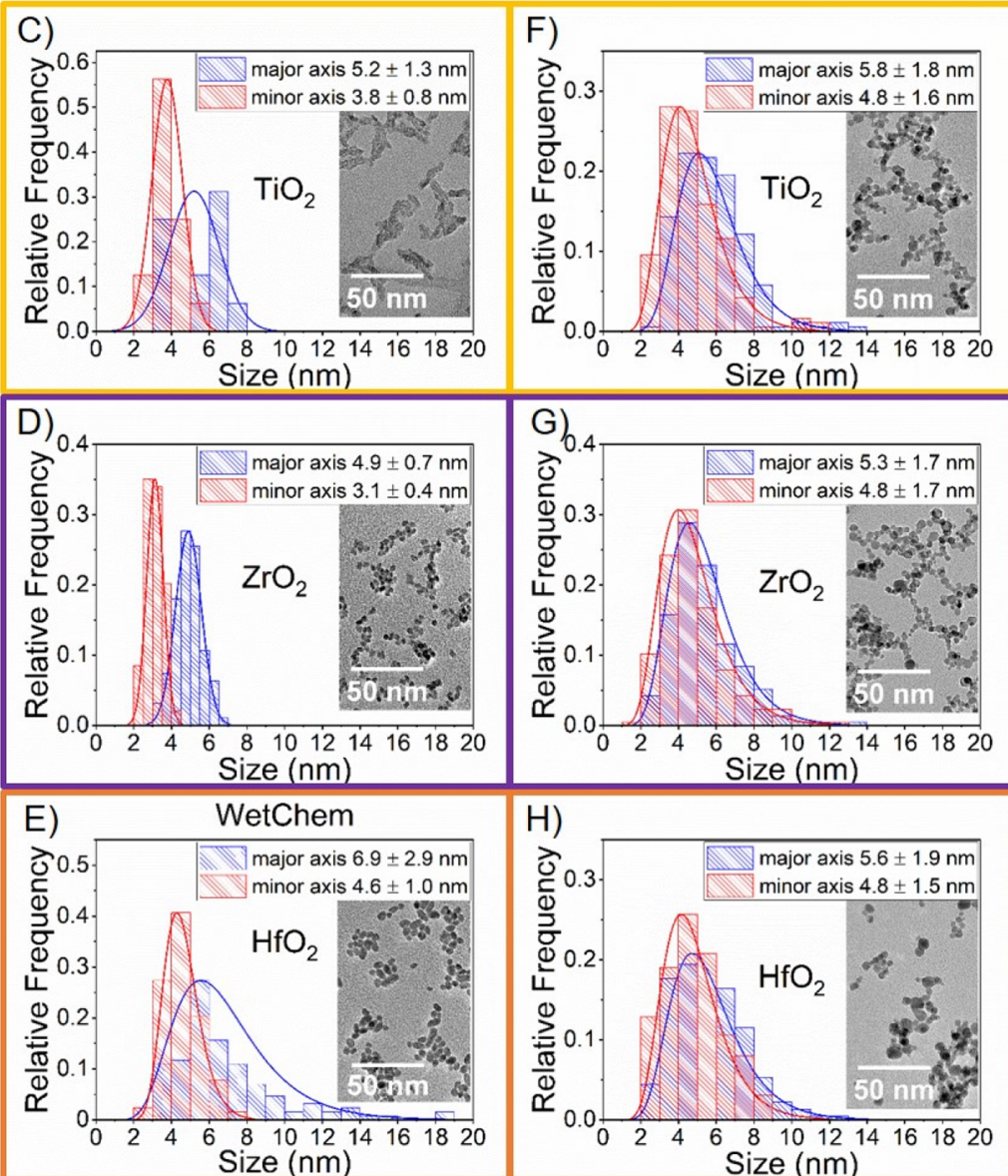

H)

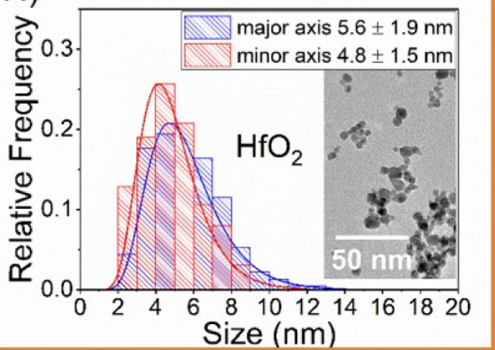

Figure 1. Schematic of the benzyl alcohol synthesis (WetChem, (A)) and flame spray pyrolysis (FSP, (B)). High-resolution transmission electron micrographs of $\mathrm{TiO}_{2}$ (yellow), $\mathrm{ZrO}_{2}$ (purple), and $\mathrm{HfO}_{2}$ (orange) nanoparticles produced by either WetChem synthesis (i-iii) or FSP synthesis (iv-vi), respectively; scale bars are $4 \mathrm{~nm}$. Transmission electron micrographs (TEM) and corresponding primary particle size distributions for $\mathrm{TiO}_{2}, \mathrm{ZrO}_{2}$, and $\mathrm{HfO}_{2}$ nanoparticles produced by either WetChem synthesis $(\mathrm{C}-\mathrm{E})$ or FSP synthesis $(\mathrm{F}-\mathrm{H})$.

radio-enhancement effects have been observed for nanoparticles with atomic numbers ranging from low (such as $\mathrm{Al}$, $\mathrm{Si}, \mathrm{Ca}, \mathrm{Ti}, \mathrm{Fe}, \mathrm{Cu}, \mathrm{Zn}$, and $\mathrm{Zr}$ ) to high (such as $\mathrm{Ag}, \mathrm{Gd}, \mathrm{Hf}, \mathrm{Pt}$, $\mathrm{Au}$, and $\mathrm{Bi}) .{ }^{10}$ Hence, the mode of action and the resulting radio-sensitization of nanoparticle-based radio-enhancement are much more complex than predicted solely based on absorption cross-section phenomena. ${ }^{11}$ Dose enhancement has been shown to be a combination of physical (secondary particle generation and release), ${ }^{9}$ chemical (reactive oxygen species concentration effects), ${ }^{12}$ and biological (molecular, cellular, and/or tissue level effects) ${ }^{5}$ responses. ${ }^{13}$ The disentangling of these processes and their contributions to the observed radio-enhancement effects remains challenging and is an active field of research. ${ }^{11}$ Nonetheless, increasing experimental and clinical evidence exists in support of nanoparticle-based radiotherapy enhancement in terms of safety and efficacy. ${ }^{8,13-16}$ Apart from gold nanoparticles, which have been widely explored in a vast range of research settings, more exotic materials such as hafnium dioxide $\left(\mathrm{HfO}_{2}\right)$ have also successfully completed clinical phase II/III studies. ${ }^{16}$ In fact, the $50 \mathrm{~nm}$ sized $\mathrm{HfO}_{2}$ nanoparticles synthesized by precipitation have been marketed by Nanobiotix as NBTXR3/ Hensify and received the European CE Mark approval in April of 2019 for the treatment of locally advanced soft tissue sarcoma via intratumoral injection. ${ }^{17}$
Despite considerable excitement in the field, ${ }^{18}$ several barriers continue to hamper clinical translation ${ }^{19}$ and more widespread adoption of other nanoparticle radio-enhancers. ${ }^{20}$ These barriers include challenges related to scalable manufacturing of high-quality nanoparticles with a narrow size distribution and high colloidal stability. ${ }^{21}$ Additionally, comparative studies of the performance of different nanoparticle radio-sensitizers in comparable settings are scarce. Available experimental studies have investigated the effect of nanoparticle size or surface functionalization but rarely address the choice of core material, thus limiting understanding of the factors (such as core material choice) that govern the nanoparticle radio-enhancement efficiencies. ${ }^{10,13,20}$ For such comparative studies, nanoparticles with comparable physicochemical properties are needed. However, the scalable production of high-quality, crystalline, uniformly sized, and small $(<100 \mathrm{~nm})$ nanoparticles poses a major translational barrier due to significant synthetic challenges. Although bottom-up wet chemical approaches offer good control over nanoparticle size, shape, crystallinity, and compositions, ${ }^{22}$ even at low temperatures, ${ }^{23}$ synthesis can be time-consuming (from several hours to several days) and is typically performed in batch mode. ${ }^{22}$ In contrast, flame spray pyrolysis (FSP) is a scalable, continuous process with production rates of up to 1 $\mathrm{kg} \mathrm{h} \mathrm{h}^{-124,25}$ and is also highly versatile, ${ }^{26}$ enabling the 
Table 1. Size Comparison of All Metal Oxide NPs Produced by WetChem- and FSP-Synthesized NPs Using Different Methods $^{a}$

\begin{tabular}{|c|c|c|c|c|c|c|c|}
\hline $\begin{array}{l}\text { Synth. } \\
\text { Route }\end{array}$ & NP & $\begin{array}{l}\bar{d}_{\text {TEM }} \\
{[\mathrm{nmm]}}\end{array}$ & $\begin{array}{l}d_{\mathrm{XRD}} \\
{[\mathrm{nm}]}\end{array}$ & $\underset{\left[\mathbf{m}^{2} \mathbf{g}^{-1}\right]}{\mathbf{S S A}}$ & $\begin{array}{l}d_{\text {BET }} \\
{[\mathrm{nm}]}\end{array}$ & $\begin{array}{l}d_{\text {DLS }} \\
{[\mathrm{nm}]}\end{array}$ & $\begin{array}{c}\mathrm{D}_{\mathrm{N}}(\mathbf{5 0}) \\
{[\mathrm{nm}]}\end{array}$ \\
\hline \multirow{3}{*}{$\begin{array}{l}\text { Wet- } \\
\text { Chem }\end{array}$} & $\mathrm{TiO}_{2}$ & $4.5 \pm 0.9$ & $4.5 \pm 0.1$ (代) & 134 & 11.8 & $38 \pm 2$ & $11 \pm 1$ \\
\hline & $\mathrm{ZrO}_{2}$ & $4.0 \pm 0.4$ & $\begin{array}{c}3.9 \pm 0.1 \\
(81 \pm 1 \% \text { 场 }) \\
5.4 \pm 0.2 \\
(19 \pm 1 \% \diamond)\end{array}$ & 71 & 13.8 & $250 \pm 2$ & $145 \pm 7$ \\
\hline & $\mathrm{HfO}_{2}$ & $5.7 \pm 1.8$ & $7.1 \pm 0.1(\diamond)$ & 76 & 7.8 & $21 \pm 1$ & $5 \pm 1$ \\
\hline \multirow[b]{3}{*}{ FSP } & $\mathrm{TiO}_{2}$ & $5.3 \pm 1.7$ & $6.0 \pm 0.2$ (引) & 235 & 6.7 & $142 \pm 6$ & $33 \pm 4$ \\
\hline & $\mathrm{ZrO}_{2}$ & $5.1 \pm 1.6$ & $6.4 \pm 0.1$ (记) & 161 & 6.1 & $158 \pm 7$ & $30 \pm 7$ \\
\hline & $\mathrm{HfO}_{2}$ & $5.2 \pm 1.7$ & $\begin{array}{c}6.2 \pm 0.3 \\
(76 \pm 3 \% \bullet) \\
6.4 \pm 0.4 \\
(24 \pm 3 \% \nabla)\end{array}$ & 89 & 6.6 & $158 \pm 13$ & $25 \pm 9$ \\
\hline
\end{tabular}

Crystalline Phases: is Tetragonal Monoclinic $\nabla$ Orthorhombic

${ }^{a} \bar{d}_{\mathrm{TEM}}$ : averaged minor and major axis from TEM images (mean $\pm \mathrm{SD}$ ). $d_{\mathrm{XRD}}$ : refined crystallite sizes based on $(1,1,1)$ (monoclinic and orthorhombic) and $(1,0,1)$ (tetragonal) peaks (size \pm SD). SSA and $d_{\mathrm{BET}}$ : specific surface area (SSA) and calculated size from nitrogen absorption $(\mathrm{BET})$ measurements. $d_{\mathrm{DLS}}$ and $D_{\mathrm{N}}(50)$ : hydrodynamic size or $z$-average (intensity distribution, $d_{\mathrm{DLS}}$ ) and the median of the number distribution $\left(D_{\mathrm{N}}(50)\right)$ from DLS measurements, respectively (mean $\left.\pm \mathrm{SD}\right)$.

reproducible synthesis of a diversity of metal, metal oxide, and multicomponent nanoparticles of almost any composition from relatively inexpensive precursors and solvents. ${ }^{27-29}$ Furthermore, compared with wet chemical processes, no solventintensive workup is necessary. ${ }^{30}$ Despite the appealing properties of FSP for scalable and sterile high-temperature production of nanoparticles, the adoption of this process for production of nanoparticles intended for biomedical applications is challenging. ${ }^{21}$ Nanoparticle products are collected in the dry state, which is considered a critical drawback due to its adverse effect on nanoparticle redispersibility. ${ }^{31-33}$ Additionally, the process-intrinsic characteristic log-normal size distribution $^{34-36}$ is considered a potential drawback that impacts the quality and safety of the product for biomedical applications. $^{37}$

In this work, we present the scalable synthesis of ultrasmall group IV metal oxide nanoparticle radio-enhancers. Ultrasmall, near-monodisperse group IV metal oxide nanoparticles were prepared either by the well-established non-aqueous wet chemical route ${ }^{38}$ in batch mode or by scalable flame aerosol technology. ${ }^{23}$ We quantitatively assess the radio-enhancement performance of the different nanoparticles in cancer cell lines with different radio-sensitivities (HT1080 and HeLa) and in fibroblasts (normal human dermal fibroblasts, NHDF) as a function of colloidal stability, uptake, and intracellular distribution. We quantify the impact of uptake and material characteristics on the radio-enhancement properties of the metal oxide nanoparticles, benchmark their efficiency against gold nanoparticles, and hence pave the way to rationalized materials selection optimized for radio-enhancement performance.

\section{RESULTS AND DISCUSSION}

Figure 1 shows the transmission electron microscopy (TEM) images and size distributions for the produced metal oxide nanoparticles. The nanoparticles synthesized by the wet chemical, surfactant-free, non-aqueous sol-gel route ${ }^{38}$ (denoted as WetChem hereafter) consistently showed an elliptic morphology with mean aspect ratios near 1.5 and comparable primary particle sizes of $4.5 \pm 0.9 \mathrm{~nm}$ for $\mathrm{TiO}_{2}, 4.0 \pm 0.4 \mathrm{~nm}$ for $\mathrm{ZrO}_{2}$, and $5.7 \pm 1.8 \mathrm{~nm}$ for $\mathrm{HfO}_{2}$ (averaged major and minor axis, $\bar{d}_{\text {TEM }}$, Table 1 ). Although the sizes were generally normally distributed with narrow standard deviations (SD), $\mathrm{HfO}_{2}$ nanoparticles exhibited a higher degree of variation with a log-normal size distribution along the major axis (Figure 1E). The elliptical shape suggests a dominant growth direction along the major axis. The characteristics of the WetChemsynthesized nanoparticle are in excellent agreement with previous literature reports on $\mathrm{TiO}_{2},{ }^{51} \mathrm{ZrO}_{2},{ }^{39,40}$ and $\mathrm{HfO}_{2}{ }^{41-43}$ nanoparticles. Nanoparticles synthesized by FSP showed primary particle sizes in the same size range, centered around $5.3 \pm 1.7 \mathrm{~nm}$ for $\mathrm{TiO}_{2}, 5.1 \pm 1.6 \mathrm{~nm}$ for $\mathrm{ZrO}_{2}$, and 5.2 $\pm 1.7 \mathrm{~nm}$ for $\mathrm{HfO}_{2}\left(\bar{d}_{\mathrm{TEM}}\right)$. In contrast to the WetChem nanoparticles, these nanoparticles were near-spherical in shape with aspect ratios of approximately 1.15 and process-intrinsic log-normal size distributions. ${ }^{26,34-36,44}$

The lattice fringes observed in high-resolution (HR)TEM micrographs (Figure $1 \mathrm{i}-\mathrm{vi}$ and Table $\mathrm{S} 1$ in the Supporting Information) indicated that all as-prepared WetChem and FSP nanoparticles were highly crystalline. X-ray diffraction analysis of the as-prepared nanoparticles showed good agreement between the crystallite diameters $\left(d_{\mathrm{XRD}}\right.$, Table 1$)$ and the observed primary particle sizes in TEM. The dominant crystal phases were tetragonal for $\mathrm{TiO}_{2}$ (in anatase mineral form) and $\mathrm{ZrO}_{2}$ and monoclinic for $\mathrm{HfO}_{2}$ nanoparticles. Coexistence of a second phase was detected in certain cases. The $\mathrm{ZrO}_{2}$ WetChem nanoparticles showed an additional monoclinic phase ( $\approx 20 \%$, based on Rietveld refinement). The occurrence of mixed phases is well documented for $\mathrm{ZrO}_{2}$ synthesized via the benzyl alcohol route. ${ }^{45}$ The phase composition and purity are highly dependent on precursor selection and concentration and temperature. ${ }^{46}$ The $\mathrm{HfO}_{2}$ FSP nanoparticles comprised a second metastable ${ }^{47}$ orthorhombic phase $(\approx 25 \%)$, in addition to the thermodynamically more stable monoclinic phase. Analysis of three independent particle batches confirmed a high reproducibility of both production methods. The XRD patterns coincide (Supporting Information, Figure S1), and mean crystallite size analysis showed relative deviations 

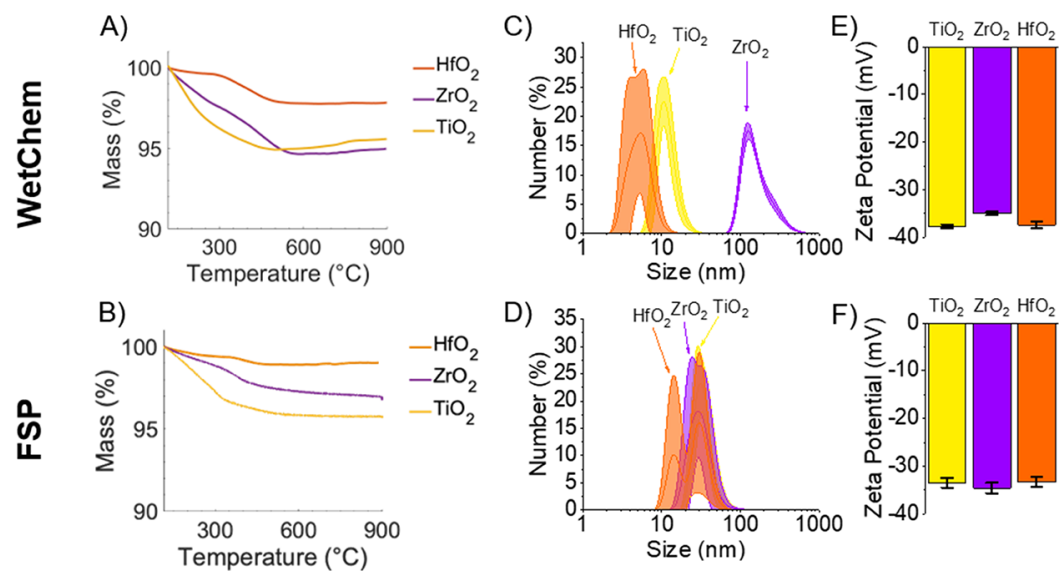

Figure 2. Thermogravimetric analysis (TGA; A, B), hydrodynamic size distributions obtained by DLS (C, D), and surface charge (zeta potential; E, F) in water of WetChem (top) and FSP-synthesized (bottom) metal oxide NPs.

between 1 and $8 \%$ for WetChem nanoparticles and between 3 and $6 \%$ for FSP-derived metal oxides (Supporting Information, Table S2). All XRD patterns showed characteristic peak broadening due to the small crystallite sizes. ${ }^{48,49}$ Rietveld refinement analysis for FSP $\mathrm{TiO}_{2}$ and $\mathrm{ZrO}_{2}$ nanoparticles can be found in the Supporting Information (Figure S2). The sizes based on $\mathrm{N}_{2}$-adsorption $\left(d_{\mathrm{BET}}\right)$ were in excellent agreement with the primary particle sizes determined based on XRD and TEM data (Table 1), indicating minor aggregation. ${ }^{50}$ Only the WetChem $\mathrm{TiO}_{2}$ and $\mathrm{ZrO}_{2}$ nanoparticles showed a slight discrepancy between $d_{\mathrm{BET}}$ and the primary particle size estimates based on crystallite $\left(d_{\mathrm{XRD}}\right)$ or microscopy sizes $\left(\bar{d}_{\mathrm{TEM}}\right)$.

The WetChem route applied in this work constitutes a robust procedure for the synthesis of high-quality sub-10 $\mathrm{nm}$ crystalline metal oxide nanoparticles at temperatures below $250{ }^{\circ} \mathrm{C}^{23}$ It is, however, considerably more time- and laborintensive than the FSP route. The aging times needed to form crystalline nanoparticles with a size below $10 \mathrm{~nm}$ via halide (or alternative) elimination have been reported to range from hours to several days for $\mathrm{TiO}_{2}$ (depending on reaction temperature), ${ }^{51} 2-3$ days for $\mathrm{ZrO}_{2},{ }^{39,40}$ and 2-4 days for $\mathrm{HfO}_{2}{ }^{41-43}$ nanoparticles. Generally, increasing the reaction times during production of metal oxide nanoparticles via the benzyl alcohol route results in a moderate growth of the primary particles (based on XRD crystal size). ${ }^{22,51,52}$ This process is exemplarily shown for the case of WetChem $\mathrm{ZrO}_{2}$ nanoparticles in which an increase in reaction time from 3 to $72 \mathrm{~h}$ led to crystal growth from 2 to $4 \mathrm{~nm}$ for the more dominant tetragonal crystal phase (Supporting Information, Figure S3). Additionally, Niederberger et al. ${ }^{51}$ observed moderate crystal growth for benzyl alcohol-made $\mathrm{TiO}_{2}$ nanoparticles. Alternatively, less time-consuming wet chemistry-based protocols have been previously investigated for the production ${ }^{53}$ of $\mathrm{HfO}_{2}$ but have failed to yield redispersible colloidally stable nanoparticle systems due to high temperature synthesis or post-processing. Although FSP synthesis is a hightemperature process in which nanoparticles are collected in the dry state, it showed primary particle quality comparable to that of WetChem synthesis.

The small primary particle size in our FSP synthesis is a result of the low molarity and low precursor-to-oxygen flow rate ratio. ${ }^{27,30}$ Monoclinic and tetragonal $\mathrm{ZrO}_{2}$ nanoparticles were reported by Mueller et al., ${ }^{24}$ who showed control over the particle diameter from 6 to $35 \mathrm{~nm}$ as a function of production rates $\left(50-600 \mathrm{~g} \mathrm{~h}^{-1}\right)$, precursor compositions, and dispersion gas flow rates. FSP offers a robust route to sterile and scalable synthesis of ultrasmall group IV metal oxide nanoparticles; however, ideal precursors (alkoxides and organometallic compounds) are more expensive than nitrate precursors, which usually give inhomogeneous particles. Furthermore, not all precursors are easily miscible, explosive precursor mixtures and conditions should be avoided, and under certain conditions, products of incomplete combustion could be present. $^{30}$

Therefore, organic contents of nanoparticles were quantified by thermogravimetric analysis (TGA) for as-prepared nanoparticles (FSP) and after workup and dialysis (WetChem). A minimal content of potentially harmful organic remnants on the nanoparticle surface (physically adsorbed or chemically bonded) after synthesis is highly favorable because it reduces the need for costly post-processing workup and reduces solvent use.

The organic contents remained well below 6 wt \% for both synthesis routes (Figure 2A,B). For example, both $\mathrm{HfO}_{2}$ nanoparticles showed a slight mass decrease $(\approx 0.5 \mathrm{wt} \%)$ in the temperature range between 110 and $300{ }^{\circ} \mathrm{C}$, which is attributed to the loss of physically adsorbed water or light organic molecules. ${ }^{40,43}$ This initial mass decrease is followed by a stepwise mass loss between 300 and $600{ }^{\circ} \mathrm{C}$, amounting to 0.5 wt \% for FSP $\mathrm{HfO}_{2}$ and 1.7 wt \% for WetChem $\mathrm{HfO}_{2}$, which is assigned to the desorption of chemically bonded organic surface remnants (see also the derivative thermogravimetric curve, DTG; Supporting Information, Figure S4). ${ }^{40}$ For the other oxides, the physisorbed organic residues were approximately $1-3$ wt $\%$ for $\mathrm{ZrO}_{2}$ and 3-4 wt $\%$ for $\mathrm{TiO}_{2}$ nanoparticles. The chemisorbed organic surface remnants were estimated as $3.0 \mathrm{wt} \%$ (WetChem) and $1.5 \mathrm{wt} \%$ (FSP) for $\mathrm{ZrO}_{2}$ nanoparticles and as 1.3 wt \% (WetChem) and 1.5 wt \% (FSP) for $\mathrm{TiO}_{2}$ nanoparticles. Generally, the nanoparticles synthesized in the flame showed lower amounts of organic residues than the WetChem nanoparticles.

For the WetChem nanoparticles, washing steps were necessary to remove excess solvents and loosely attached organic residues for successful transfer of the nanoparticles into water. Except for $\mathrm{ZrO}_{2}$, the transfer of WetChem nanoparticles to water resulted in de-agglomerated near-transparent dispersions, even at concentrations $>5 \mathrm{mg} \mathrm{mL}^{-1}$. The high water dispersibility in those systems might stem from chloride and benzyl group terminated surfaces. ${ }^{5455}$ The nanoparticle 

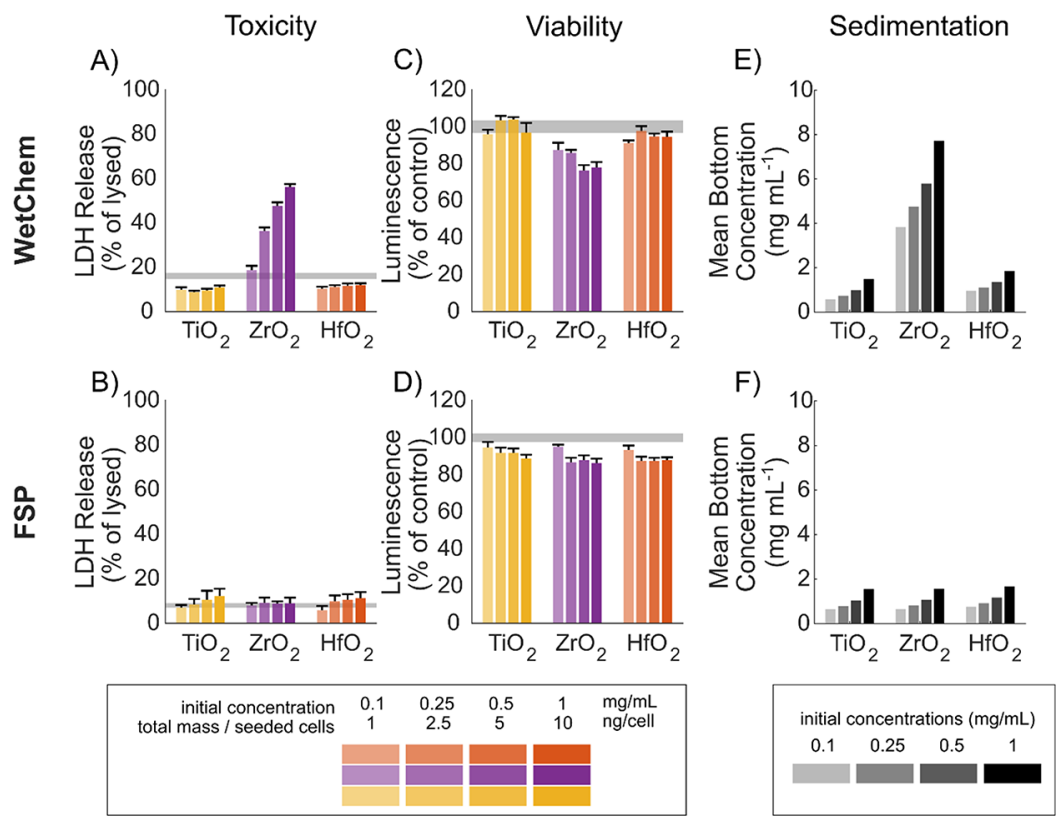

Figure 3. Cytotoxicity (lactate dehydrogenase release (LDH); A, B), cell viability (luminescence showing metabolic activity; C, D), and in vitro sedimentation calculations (E, F) following $24 \mathrm{~h}$ incubation of fibrosarcoma cells (HT1080) with WetChem-synthesized (A, C, E) and FSPsynthesized (B, D, F) group IV metal oxide NPs. The corresponding total NP mass per seeded cell (ng cell ${ }^{-1}$ ) is shown next to the administered NP incubation concentration $\left(\mathrm{mg} \mathrm{mL}^{-1}\right)$. In $\mathrm{A}-\mathrm{D}$, the gray horizontal bar shows the mean $\pm \mathrm{SD}$ values of the cells of the negative control (untreated). Results are from $N \geq 2$ independent biological experiments, and error bars are calculated using Gaussian error propagation.

number medians were $5\left(\mathrm{HfO}_{2}\right)$ and $11 \mathrm{~nm}\left(\mathrm{TiO}_{2}\right)$, respectively, indicating minor agglomeration (Table 1 and Figure 2C). Despite extensive washing, the agglomerate sizes of $\mathrm{ZrO}_{2}$ in water could not be decreased, and the mean number size (around $145 \mathrm{~nm}$ ) remained considerably higher compared with the other oxides (Table 1 and Figure 2C). Additional surface modification might be used to reduce agglomeration in polar solvents, as shown by Kockmann et al. ${ }^{56}$ Nanoparticles synthesized by FSP were readily waterdispersible directly after synthesis, and no workup was required. The hydrodynamic sizes $\left(d_{\text {DLS }}\right)$ of these particles were similar to each other, and their number medians $\left(D_{\mathrm{N}}(50)\right)$ were near $30 \mathrm{~nm}$, indicating minor agglomeration in water and cell culture medium (Table 1, Figure 2D, and Figures S4 and S5 in the Supporting Information). Metal oxide nanoparticles made in flame reactors are typically hydrophilic as they have a high surface density of hydroxyl groups ${ }^{57-59}$ and hence disperse well in aqueous media. Note that the discrepancy between $\bar{d}_{\mathrm{TEM}}$ and $d_{\mathrm{DLS}}$ originates from partial agglomeration, the difference between intensity (DLS) and number-based (TEM) distribution as well as overestimation of the average hydrodynamic size of fractal-like nanoparticles by DLS. $^{60}$ Colloidal stability and sedimentation measurements performed using the method described by Spyrogianni et al. ${ }^{61}$ confirm the high colloidal stability of WetChem $\mathrm{TiO}_{2}$ and $\mathrm{HfO}_{2}$. These measurements further indicate that the sedimentation behavior of all FSP nanoparticles is highly similar and comparable to that observed for $50 \mathrm{~nm}$ gold nanoparticles (Supporting Information, Figures S6 and S7). These findings are well in line also with agglomerate sizes observed for air-dried nanoparticle suspensions in TEM (Supporting Information, Figure S8). Zeta potential values measured in 2\% PBS were consistently negative (range between -33 and $-37 \mathrm{mV}$, Figure 2E,F) and minimally affected by the type of oxide or the synthesis route. Taken together, the WetChem-synthesized oxides showed differences in colloidal behavior. $\mathrm{HfO}_{2}$ and $\mathrm{TiO}_{2}$ nanoparticles were highly dispersible and colloidally stable, whereas $\mathrm{ZrO}_{2}$ nanoparticles showed significant agglomeration. The different FSP-synthesized oxide nanoparticles exhibited comparable physicochemical characteristics and high water dispersibility with only minor agglomeration. The above results indicate that although gram-scale batches of high-quality group IV metal oxides are achievable via the benzyl alcohol route, ${ }^{39,51,62}$ continuous flow processing, ${ }^{22,63}$ including flame spray pyrolysis, offers a promising strategy for increasing the production rates $(\mathrm{mg}$ or $\mathrm{g} \mathrm{day}^{-1}$ ) to pilot-plant scales $\left(\mathrm{kg} \mathrm{day}^{-1}\right)^{63}$ with uncompromised product quality.

Following physicochemical characterization of the asprepared nanoparticles, their toxicity (in the absence of radiation) was investigated against different cell types, including dermal fibroblasts (NHDF), fibrosarcoma cells (HT1080), and the widely researched HeLa cells (adenocarcinoma). The HT1080 and HeLa cell lines were selected as wellestablished cancer cell lines with relatively high radioresistance. ${ }^{64,65}$ Primary fibroblasts were chosen as representative noncancerous cells. Luminescent ATP quantification (indicating metabolically active cells) and lactate dehydrogenase $(\mathrm{LDH})$ release (indicating membrane damage) were selected as sensitive endpoints to assess the nanoparticle effects on cell viability and to determine a subtoxic nanoparticle dose for radio-enhancement experiments. The results are shown in Figure 3A-D for HT1080 and Figures S9 and S10 for HeLa and NHDF, respectively. The two assays showed excellent agreement and revealed only minor effects on cell viability for nanoparticle concentrations up to $1 \mathrm{mg}$ per $\mathrm{mL}$ (equivalent to a total applied dose of $10 \mathrm{ng}$ per seeded cell) (Figure 3A-D). Only the WetChem $\mathrm{ZrO}_{2}$ nanoparticles showed a detectable effect on the cell viability of HT1080 cells 

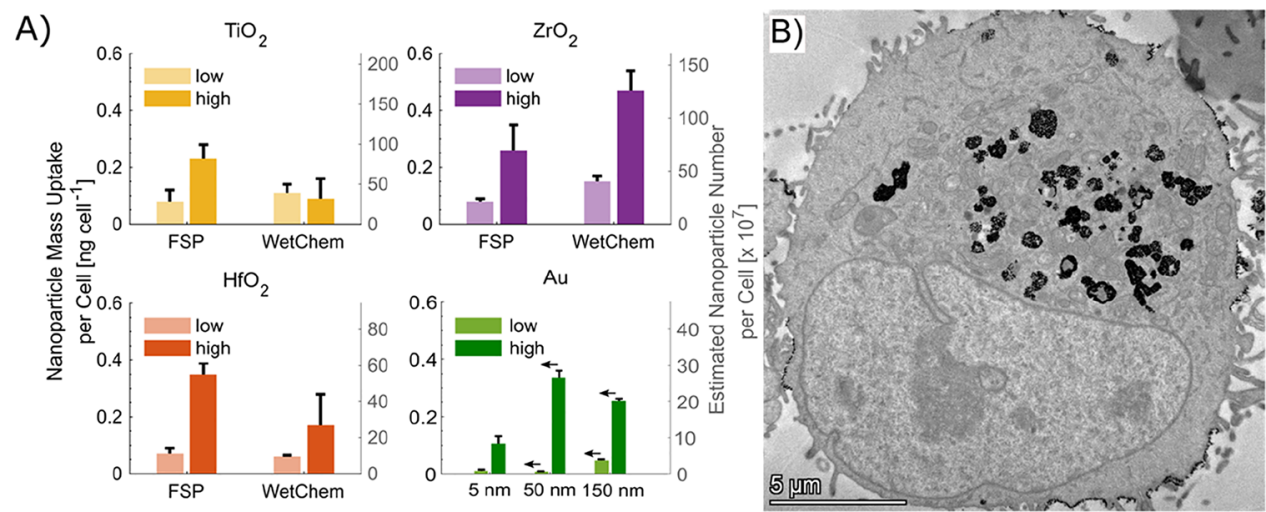

D)
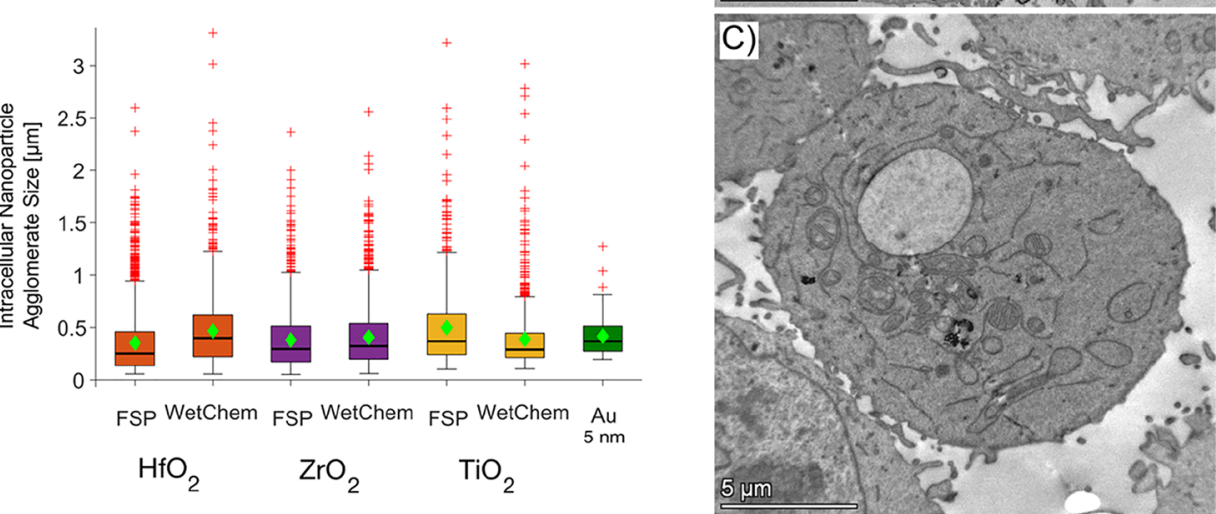

Figure 4. Mass uptake quantification (ICP-MS) of FSP- and WetChem-synthesized metal oxide and Au NPs (5, 50, and 150 nm) in HT1080 fibrosarcoma cells for two different administered NP doses (low: $1 \mathrm{ng} \mathrm{cell}{ }^{-1}$, high: $5 \mathrm{ng} \mathrm{cell}{ }^{-1}$ ) after $24 \mathrm{~h}$ of NP incubation (A). Right $y$-axis denotes the mass equivalent estimated number of NPs with $5 \mathrm{~nm}$ size. Black arrows show correspondence to only the left $y$-axis. Representative scanning transmission electron micrographs of $\mathrm{HT} 1080$ cells showing intracellular WetChem $\mathrm{HfO}_{2}$ (B) and Au NPs (C). Intracellular NP agglomerate size (Feret diameter) estimated based on STEM images (D) for the different types of NPs. Boxes range from the 25th to 75th percentile and include the median (black bars) and mean (green diamonds). Whiskers extend to the most extreme values not considered outliers. Red crosses denote outliers.

(Figure 3) but not on the other two cell lines (Supporting Information, Figure S9 (HeLa) and Figure S10 (NHDF)).

The effect on HT1080 cell viability might at least partially be explained by the higher hydrodynamic size of WetChem $\mathrm{ZrO}_{2}$ and thus faster sedimentation, ${ }^{66}$ resulting in higher cellular uptake (vide infra for results on cellular uptake). ${ }^{61}$ To confirm this hypothesis, nanoparticle sedimentation and diffusion were calculated using the modified distorted grid model. ${ }^{67}$ Considering the average hydrodynamic size of particles in the cell medium, the bottom concentration (lowest $10 \mu \mathrm{m}$ of a well) was estimated to be at least five times higher for WetChem $\mathrm{ZrO}_{2}$ than for the other oxide nanoparticles (Figure 3E,F). The higher tolerance by HeLa and NHDF cells illustrates the varying uptake (Figure 4 and Figure S11 in the Supporting Information) and susceptibility of different cell lines to nanoparticle effects (Figure 3 and Figures S9 and S10 in the Supporting Information). Based on the above cytotoxicity and cell viability studies, two subtoxic administered total doses normalized to cell seeding number, i.e., 1 and $5 \mathrm{ng}$ per seeded cell, were selected for further studies.

After confirming the cytocompatibility of the selected nanoparticle doses, the nanoparticle uptake and intracellular distribution were investigated in HT1080 (Figure 4), HeLa and NHDF (Supporting Information, Figure S11) cells by inductively coupled plasma mass spectroscopy (ICP-MS) and (scanning) transmission electron microscopy. As evident from the scanning transmission micrographs, uptake measurements include intracellular nanoparticles as well as those firmly attached to the outer cellular membrane (Figure 4). For the FSP nanoparticles, mass uptake was comparable for the different oxides, reaching values of approximately $0.1 \mathrm{ng}$ $\mathrm{cell}^{-1}$ for the lower administered dose and approximately 0.3 ng cell ${ }^{-1}$ for the higher administered dose (Figure 4A). The nanoparticle mass uptake was also converted into nanoparticle number concentration per cell, with estimated cell uptakes of $81 \times 10^{7}, 71 \times 10^{7}$, and $54 \times 10^{7}$ nanoparticles for the $\mathrm{TiO}_{2}$, $\mathrm{ZrO}_{2}$, and $\mathrm{HfO}_{2}$ FSP nanoparticles, respectively. Although the cellular mass uptake was very comparable for the FSP nanoparticles (6\% deviation in the high dose), greater variations were observed for the WetChem nanoparticles. Expectedly and well in line with the large hydrodynamic size and the dosimetry calculations (Supporting Information, Figure S5), the highest uptake was observed for the WetChem $\mathrm{ZrO}_{2}$ nanoparticles. Interestingly, elemental analysis showed that compared with all oxides, the citrate-stabilized $5 \mathrm{~nm}$ gold nanoparticles showed lower cell uptakes of 0.01 and $0.1 \mathrm{ng}$ cell $^{-1}(<1 \%$ of total, Figure 4A), despite the fact that dosimetry calculations show similar mass concentrations at the bottom of the well for gold and metal oxides. Larger gold nanoparticles, namely, 50 and $150 \mathrm{~nm}$, were internalized more readily and to an extent comparable to the FSP metal oxide nanoparticles. The uptake results are in good agreement with previous studies in a similar setting ${ }^{68}$ and in line with literature for other cell lines at comparable nanoparticle administration concentrations (Supporting Information, Table S3). The lower uptake for 5 $\mathrm{nm}$ gold nanoparticles was also observed in the scanning 
WetChem

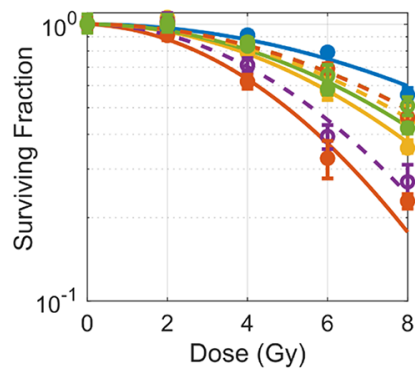

FSP

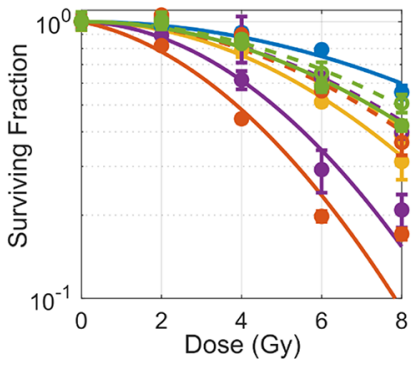

Control $\overline{9}$

$\mathrm{TiO}_{2} \Phi$ low high

$\mathrm{ZrO}_{2} \Phi$ low $\overline{\mathbf{Q}}$ high

$\mathrm{HfO}_{2} \Phi$ low high

Au $\Phi$ low $\overline{\underline{T}}$ high

Figure 5. HT1080 cell survival fraction as a function of irradiation dose (Gy) of $150 \mathrm{kVp} \mathrm{X-rays} \mathrm{with} \mathrm{or} \mathrm{without} \mathrm{prior} \mathrm{incubation} \mathrm{with} \mathrm{low} \mathrm{or} \mathrm{high}$ NP doses (low: $1 \mathrm{ng} \mathrm{cell}^{-1}$; high: $5 \mathrm{ng} \mathrm{cell}^{-1}$ ) of different metal oxides and $5 \mathrm{~nm}$ gold NPs for 24 h. Lines through data show linear quadratic survival curve fits for low (dashed) and high (solid) NP concentrations. Left: WetChem-synthesized NPs. Right: FSP-synthesized NPs. Results shown as mean $\pm \mathrm{SD}(n=3)$.
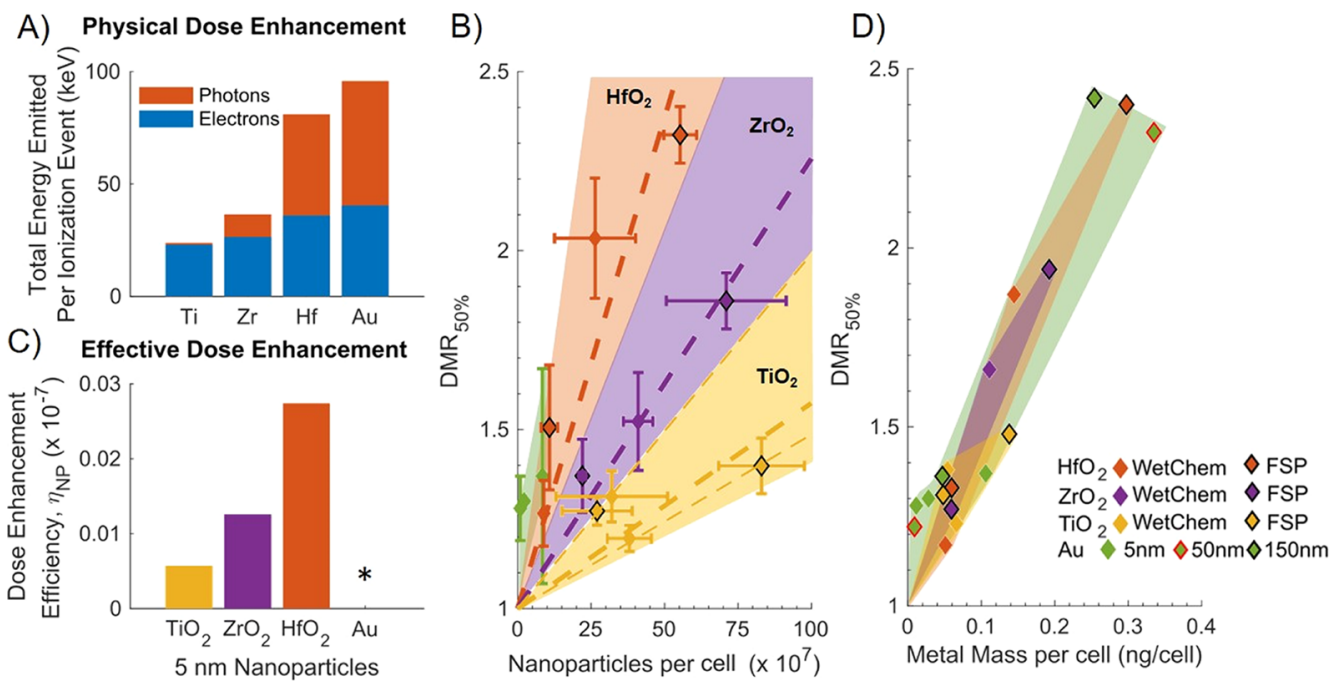

Figure 6. Dose enhancement efficiencies for different NPs. Physical dose enhancement as total energy emitted from a single $20 \mathrm{~nm} \mathrm{Ti}$, $\mathrm{Zr}$, or $\mathrm{Hf}$ $\mathrm{NP}$ and its contributions from secondary electrons (Auger, photo, and Compton electrons) and photons following an ionizing event (Monte Carlo simulation data obtained from McMahon et al. $\left.{ }^{73}\right)(\mathrm{A})$. Mean dose modifying ratio $(N=2)$ and linear correlation with uptake of the different group IV oxide NPs (WetChem and FSP TiO, $\mathrm{ZrO}_{2}$, and $\mathrm{HfO}_{2}$ ) and $5 \mathrm{~nm} \mathrm{Au} \mathrm{NPs} \mathrm{(B);} \mathrm{bold} \mathrm{dashed} \mathrm{lines} \mathrm{show} \mathrm{linear} \mathrm{fit} \mathrm{with} R^{2}=0.85\left(\mathrm{HfO}_{2}\right), R^{2}=$ $0.97\left(\mathrm{ZrO}_{2}\right)$, and $R^{2}=0.59\left(\mathrm{TiO}_{2}\right)$; thin dashed lines show best linear fit for lowest and highest $\mathrm{TiO}_{2} \mathrm{NP}$ uptakes. Fitted dose enhancement efficiencies per NP, $\eta_{\mathrm{NP}}$, irrespective of the synthesis method (C). DMR ${ }_{50 \%}$ of $5 \mathrm{~nm}$ Au NPs could not be computed due to nonlinearity (indicated by an asterisk). Experimentally observed dose enhancement as a function of metal mass per cell (D). Shaded areas in (B) and (D) are visual aids showing the NP effectiveness area.

transmission electron micrographs (Figure 4C). From the STEM images, it can also be observed that intracellular nanoparticle agglomerates were formed (Figure 4B,C and Figure S12 in the Supporting Information). The intracellular agglomerate characteristics were quantified and showed an average Feret diameter in the range between 0.4 and $0.5 \mu \mathrm{m}$, regardless of the type of metal/metal oxide or synthesis route, which is in good agreement with previous work on gold nanoparticles ${ }^{69}$ (Figure 4D and Figure S12 in the Supporting Information).

It was also observed that these agglomerates can cluster together to form large nanoparticle assemblies well above the size of $1 \mu \mathrm{m}$ (Figure 4B,D). The nanoparticle uptake estimated based on STEM image analysis relating the intracellular nanoparticle area to the cell area shows trends in line with the ICP-MS measurements (Supporting Information, Figure S13). Taken together, the similar physicochemical and water dispersibility characteristics of the FSP-synthesized metal oxides led to a comparable mass uptake into cells, which allows direct comparison of their radio-enhancement efficacies.
In contrast, the WetChem nanoparticles showed a more variable uptake that scaled with their colloidal size and stability, i.e., low uptake for small and stable $\left(\mathrm{TiO}_{2}\right.$ and $\left.\mathrm{HfO}_{2}\right)$ nanoparticles and high uptake for agglomerated, rapidly sedimenting $\left(\mathrm{ZrO}_{2}\right)$ nanoparticles.

Following comprehensive physicochemical characterization of the nanoparticles and the cellular uptake, the radiosensitization effects were assessed in a well-standardized $e x$ vivo setup using a tissue phantom and relatively radio-resistant sarcoma cells (HT1080), cervical adenocarcinoma cells (HeLa), and normal fibroblasts (NHDF). The radiosensitization effects of WetChem- and FSP-synthesized nanoparticles were assessed under comparable conditions and benchmarked against equi-dosed $5 \mathrm{~nm}$ Au nanoparticles. We note that $24 \mathrm{~h}$ incubation of cells with nanoparticles led to a viability after 7 days (long-term effect) that was comparable to that of nanoparticle-free control cells, indicating no damaging effect of nanoparticles in the absence of radiation (Supporting Information, Figures S14 and S15). Only the high $\mathrm{ZrO}_{2}$ WetChem nanoparticle concentration showed a 

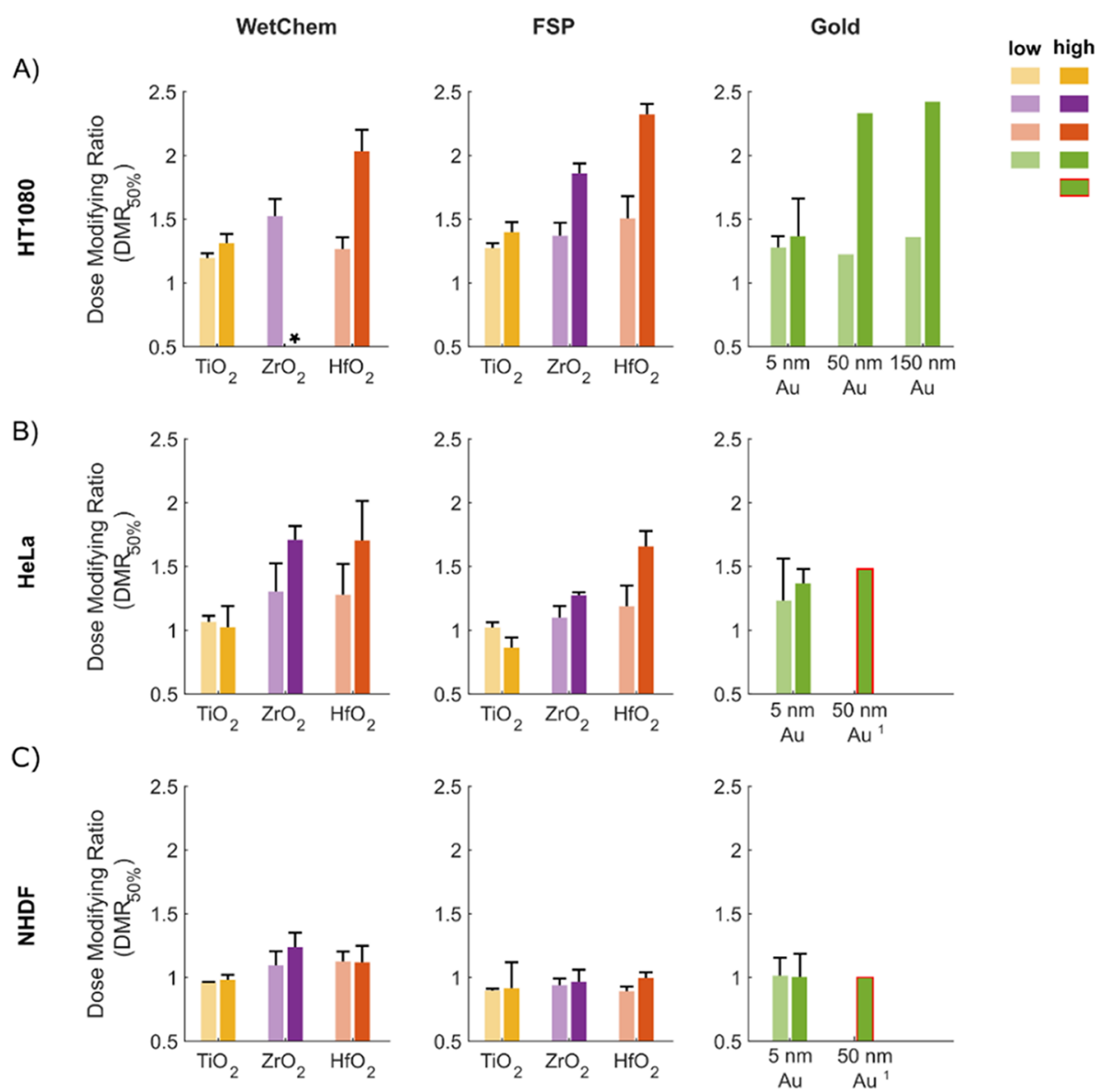

Figure 7. Radio-enhancement effects $\left(\mathrm{DMR}_{50 \%}\right)$ of WetChem-produced and FSP-produced metal oxide NPs and Au NPs for two cancer cell lines (HT1080 (A) and HeLa (B)) and one noncancerous cell line (NHDF (C)). Results are given for two different administered NP doses (low: 1 ng cell $^{-1}$, high: $5 \mathrm{ng}$ cell $^{-1}$ ). Results are derived as mean $\pm \mathrm{SD}$ from at least $N=2$ independent biological experiments (only in the case of Au 50 and $150 \mathrm{~nm}, N=1)$ and corresponding linear quadratic survival curve fits. Asterisk: viability $<80 \%$ for sham $(0 \mathrm{~Gy})$ irradiation observed compared with NP free control cells.: ${ }^{1}$ Data for $50 \mathrm{~nm}$ Au NPs in HeLa and NHDF cells extracted from Neuer et al. ${ }^{68}$ for a comparable setting.

significantly decreased long-term cell viability and was excluded from further analysis.

With irradiation, the viability of the HT 1080 cells expectedly decreased in a dose-dependent linear quadratic fashion (Figure 5). Approximately $80 \%$ of control cells (no nanoparticle treatment) survived an irradiation dose of $6 \mathrm{~Gy}$. The $D_{50 \%}$ value, indicating the irradiation dose that kills $50 \%$ of the cells, was around $9 \mathrm{~Gy}$. With nanoparticles, the $D_{50 \%}$ decreased as a function of increasing nanoparticle concentration and increasing atomic number. Experiments showed a clear trend of the $D_{50 \%}\left(\mathrm{TiO}_{2}>\mathrm{ZrO}_{2}>\mathrm{HfO}_{2}\right)$ following the inverse sequence of atomic number $(\mathrm{Ti}(Z=22)<\operatorname{Zr}(Z=40)<\operatorname{Hf}(Z=72))$ for both low and high nanoparticle concentrations (Supporting Information, Table S4). The only exception is WetChem $\mathrm{ZrO}_{2}$ nanoparticles, which show a lower $D_{50 \%}$ than $\mathrm{HfO}_{2}$ due to their larger hydrodynamic size resulting in higher uptake. Radioenhancement quantification can be expressed as the dose modifying ratio (DMR) by dividing the irradiation $D_{50 \%}$ of the cells without nanoparticles by the value with nanoparticles: $\mathrm{DMR}_{50 \%}=\frac{D_{\mathrm{C}, 50 \%}}{D_{\mathrm{NP}, 50 \%}} \cdot{ }^{70}$ Hence, the $\mathrm{DMR}_{50 \%}$ was following the order of the atomic number $\left(\mathrm{HfO}_{2}>\mathrm{ZrO}_{2}>\mathrm{TiO}_{2}\right)$ for the metal oxides. The $5 \mathrm{~nm}$ sized gold nanoparticles performed similarly to $5 \mathrm{~nm}$ sized $\mathrm{TiO}_{2}$ nanoparticles in the current setting (Supporting Information, Table S4). This result is likely attributable, at least in part, to the reduced cellular uptake of the gold compared with the group IV metal oxide nanoparticles. For comparison, we performed additional radioenhancement experiments using 50 and $150 \mathrm{~nm}$ gold nanoparticles (Supporting Information, Figure S16). Higher uptake and higher $\mathrm{DMR}_{50 \%}$ values were observed for 50 and $150 \mathrm{~nm}$ than for $5 \mathrm{~nm}$ gold nanoparticles; however, dose enhancement effects were very similar to those for $5 \mathrm{~nm} \mathrm{HfO}_{2}$ at the same mass uptake.

At comparable uptake, the dose enhancement increases with the nanoparticle atomic number, suggesting that the observed effects are, at least in part caused by the different mass attenuation cross-sections and secondary particle emissions, next to chemical and biological enhancements mechanisms.

Figure $6 \mathrm{~A}$ shows a comparison of the total energy emitted from a nanoparticle following an ionizing event as calculated based on Monte Carlo simulations ${ }^{55}$ for the different types of nanoparticles. Following an ionization event on the surface of a $\mathrm{Hf}, \mathrm{Zr}$, $\mathrm{Ti}$, or $\mathrm{Au}$ nanoparticle, secondary electrons (such as photo and Auger electrons) and fluorescent photons are created, delivering a high dose locally. This physical dose enhancement (based on the total energy emission from a nanoparticle) suggests that hafnium-based particles could be more effective than zirconium-based particles followed by titanium-based particles. We calculated the biological effectiveness of our nanoparticles in terms of DMR, which is a concept 
similar to the relative biological effectiveness $\left(\mathrm{RBE}=\frac{D_{\mathrm{X}}}{D_{\mathrm{I}}}\right.$, where $D_{\mathrm{X}}$ is the dose of $\mathrm{X}$-ray radiation and $D_{\mathrm{I}}$ is the dose of densely ionizing radiation leading to the same cell-killing level). ${ }^{71}$ From a physical point of view, the RBE for nanoparticles scales linearly with their concentration in the tumor cells. ${ }^{71,72}$ Correspondingly, our metal oxide nanoparticle DMRs, irrespective of the synthesis method, were analytically described by a linear function: $\mathrm{DMR}_{\mathrm{NP}}=1+\eta_{\mathrm{NP}} \#_{\mathrm{NP}}$, where $\eta_{\mathrm{NP}}$ is the nanoparticle dose enhancement efficiency and $\#_{\mathrm{NP}}$ is the intracellular and the cell membrane-attached number of $\mathrm{TiO}_{2}, \mathrm{ZrO}_{2}$, or $\mathrm{HfO}_{2}$ nanoparticles (Figure 6B). From this result, it can be observed that the $\mathrm{HfO}_{2}$ and $\mathrm{ZrO}_{2}$ nanoparticles are approximately four and two times more effective than $\mathrm{TiO}_{2}$ nanoparticles, respectively, mirroring the ratios from the energy emission predictions per nanoparticle (Figure 6C). When DMRs are expressed as a function of metal mass per cell, highest DMRs are observed for $\mathrm{HfO}_{2}$ and the 50 and $150 \mathrm{~nm}$ sized Au nanoparticles (Figure 6D). While the uptake was very similar for all FSP-made nanoparticles, hence allowing direct comparison of the DMR values at comparable uptake, comparison with WetChem and gold nanoparticles at the exact same uptake is more challenging. Nonetheless, since DMR values show a linear dependence on uptake, Figure $6 \mathrm{~B}, \mathrm{D}$ provides important insights on performance for the different nanoparticles at comparable number and mass concentrations, respectively.

Analogous to the HT1080 cells, nanoparticle dose- and atomic number-dependent radio-enhancement effects were also found in HeLa (adenocarcinoma) cells, although with an overall lower effect (Figure 7 and Figure S17 in the Supporting Information). Varying dose modifying ratios between different cell lines for the same nanoparticles are not surprising because radio-sensitization effects have been shown to be strongly cell line-dependent. ${ }^{74,75}$ While the DMRs correlate linearly with uptake in a certain cell line, the values still vary widely between cell lines. In fibroblasts (NHDF), no significant radiosensitization effect was found (DMRs near 1). This might be caused by the lower uptake (of the metal oxide nanoparticles, see Figure S11 in the Supporting Information) and/or higher tolerance to $\operatorname{ROS}^{76}$ compared with tumor cells. No long-term effect on cell viability was observed in HeLa and NHDF cells in the absence of radiation, not even for WetChem $\mathrm{ZrO}_{2}$, indicating that both radio-enhancement properties and cytotoxicity are strongly dependent on cell line (Supporting Information, Figures S14 and S15). A summary of all survival fractions for different cell lines can be found in Figure S18 in the Supporting Information. Overall, in the two cancer cell lines, the DMRs were highest for $\mathrm{HfO}_{2}$ and $\mathrm{Au} 50$ and $150 \mathrm{~nm}$ followed by $\mathrm{ZrO}_{2}$ and $\mathrm{TiO}_{2}$ nanoparticles. The FSPsynthesized nanoparticles showed higher DMRs than the WetChem-synthesized nanoparticles, which is in line with the observed higher nanoparticle uptake. The biological effects of the different crystal phases and their influence on cytotoxicity and radio-enhancement properties remain to be investigated using phase pure nanoparticles.

A comparison of the observed effects with the literature is challenging due to the various methodologies reported, which further highlights the need for comparative studies that directly compare different nanomaterials in the same experiment. Youkhana et al. ${ }^{77}$ found nanoparticle concentration-dependent DMRs between 1.2 and 1.7 for $30 \mathrm{~nm}$ amine-functionalized $\mathrm{TiO}_{2}$ nanoparticles at $80 \mathrm{kVp} \mathrm{X}$-rays. In contrast, for $0.5 \mathrm{mM}$
$\mathrm{TiO}_{2}$ nanoparticles, DMRs of 1.21 and 1.27 were found for $\mathrm{HaCaT}$ and DU145 cells, respectively. Our results show similar DMRs of 1.3 and 1.4 in HT1080 cells using a slightly lower concentration of $0.42 \mathrm{mM}$ for WetChem and FSP $\mathrm{TiO}_{2}$ nanoparticles, respectively.

For the most researched $\mathrm{Au}$ nanoparticles, literature values for these particles in the same cell lines (HT1080 and HeLa) can be found. Joh et al. found a DMR of 1.16 for $1 \mathrm{mM} 12 \mathrm{~nm}$ core pegylated Au nanoparticles in clonogenic HT1080 cell survival assays $(150 \mathrm{kVp}){ }^{78}$ For HeLa cells, Chithrani et al. found a DMR of $1.2(220 \mathrm{kVp})$ for $14 \mathrm{~nm}$ nanoparticles with an uptake of $\sim 0.0001 \mathrm{ng} \mathrm{cell}^{-1}$. $^{69}$ These values are comparable to our findings for $5 \mathrm{~nm}$ Au nanoparticles in HeLa (DMR 1.23 with $0.004 \mathrm{ng} \mathrm{cell}^{-1}$ ) and HT1080 cells (DMRs 1.28 and 1.37 for 0.01 and $0.1 \mathrm{ng}$ cell $^{-1}$, Figure $\left.7 \mathrm{~A}, \mathrm{~B}\right)$. Although we used a metabolic assay instead of a clonogenic assay, there is evidence that the conclusions drawn from both assays are concordant. ${ }^{13,77,79}$ We further confirmed in a small-scale experiment that both assays are in line with each other (Supporting Information, Figure S19).

Nonlinearity has been observed for $5 \mathrm{~nm} \mathrm{Au}$ nanoparticles (Figure 6C), where a nanoparticle dose exceeding $5 \mathrm{ng}$ cell $^{-1}$ led to higher uptake $(2 \times)$ and cytotoxicity without additional dose enhancement (Supporting Information, Figure S16). These findings are in good agreement with Zhang et al. ${ }^{80}$ reporting higher toxicity for $4.8 \mathrm{~nm}$ Au nanoparticles and lower dose enhancement with increasing concentration compared to larger nanoparticles. Similarly, Liu et al. reported a nonlinear dependence of the radio-enhancement on the concentration for $15 \mathrm{~nm} \mathrm{Au}$ nanoparticles in HeLa cells. ${ }^{81}$ They proposed a radio-sensitization mechanism based on the production of hydroxyl radicals and showed a decreased ROS production with increasing nanoparticle concentration. For $50 \mathrm{~nm}$ sized Au nanoparticles, Chithrani et al. found an uptake of $\sim 0.01 \mathrm{ng}$ cell $^{-1}$ into HeLa cells with DMRs of $1.43(220 \mathrm{kVp})$ and 1.66 $(105 \mathrm{kVp})$. These values are well in line with the DMR of 1.5 $(150 \mathrm{kVp})$ for $50 \mathrm{~nm} \mathrm{Au}$ nanoparticles in HeLa cells and comparable the ones for $\mathrm{HfO}_{2}$ (DMR FSP high 1.66 and WetChem high 1.70, Figure 7B). Taken together, FSPsynthesized hafnia nanoparticles outcompeted $5 \mathrm{~nm} \mathrm{Au}$ nanoparticles in radio-enhancement due to the higher uptake and better cytocompatibility and performed comparably to 50 and $150 \mathrm{~nm}$ sized $\mathrm{Au}$ nanoparticles, hence rationalizing the promising clinical results found for hafnia. Note that radioenhancement effects are, in addition to nanomaterial composition, strongly dependent on additional factors. Cell type, cell age, and nanoparticle suspension stability might directly or indirectly (via altered uptake) ${ }^{82}$ influence radioenhancement effects, which should therefore always be assessed as a function of nanoparticle uptake.

Importantly, the flame spray pyrolysis production process can be readily scaled up without compromises in product quality. While this study is the first to report the FSP synthesis of $\mathrm{HfO}_{2}$, large-scale production of FSP-synthesized metal oxides, including $\mathrm{TiO}_{2}{ }^{83,84}$ and $\mathrm{ZrO}_{2},{ }^{24,85}$ has been achieved, albeit with larger particle size. Typically, FSP-synthesized particles are produced exhibiting larger primary particle sizes (between 5 and $500 \mathrm{~nm}$ ) than the ones reported here (size distributions between 2 and $10 \mathrm{~nm}) .{ }^{86}$ Flame-synthesized $\mathrm{TiO}_{2}$ is also commercially available (e.g., P25, P90 by Degussa/ Evonik). To demonstrate scale-up of the synthesis of ultrasmall group IV metal oxide nanoparticles as an important step in the translation, we produced a large batch $(50 \mathrm{~g})$ of the best 
performing FSP nanoparticles $\left(\mathrm{HfO}_{2}\right)$ at a production rate of $15 \mathrm{~g} \mathrm{~h}^{-1}$ and a yield of $>82 \%$. Particle characteristics are primarily determined by the high-temperature particle residence times, ${ }^{85}$ which have been selected here to yield ultrasmall nanoparticles (around $5 \mathrm{~nm}$ ). While we report the first continuous FSP production of $\mathrm{HfO}_{2}$, similar and even higher production $\left(>100 \mathrm{~g} \mathrm{~h}^{-1}\right)$ rates have been achieved in flame spray pyrolysis pilot scale reactors for other oxides ${ }^{25,85}$ and larger particle sizes. Production rates could be further increased in a straightforward manner by using multiple flames. Most importantly, we also show that the nanoparticle properties and radio-enhancement performance of the scaledup particles were no different from those of the small-scale batch (Supporting Information, Figures S20 and S21). This direct demonstration of scalability illustrates the feasibility for large-scale production of ultrasmall group IV metal oxides necessary for future clinical application.

\section{CONCLUSIONS}

Taken together, we present a route to the scalable and sterile high-temperature production of ultrasmall, near-monodisperse, water-dispersible metal oxide nanoparticles with radioenhancement activity. Flame spray pyrolysis enables scalable production of high-quality nanoparticle radio-enhancers, hence offering an attractive route to systematic investigations advancing the rationalized design of nanoparticle-enhanced radiotherapy agents. We further demonstrate in a direct comparison of morphologically similar nanoparticles with varying atomic number, that the radio-enhancement properties at ortho-voltage energies are dominated by physical effects, strongly depend on atomic number, and linearly depend on nanoparticle uptake. The approach presented here offers a route to rationalized material design and radio-enhancement performance optimization in cellular systems, which allow quantitative evaluation of the radio-enhancement performance under well-controlled conditions. By rationalizing material selection and providing a scalable and sterile route to the manufacturing of these materials, the presented strategy is foreseen to decisively contribute to the reduction of animal experiments in accordance with the $3 \mathrm{R}$ principles. ${ }^{87}$ More concretely, the direct comparison to gold supplies the rational for further clinical exploration of hafnia nanoparticles, which might be produced in the future via flame pyrolysis as a scalable, sterile, cost-effective, and robust alternative to current synthesis routes. This work provides important insights needed to guide future developments in the field of nanoparticle radioenhancers and, most crucially, provides scientists with a method to produce these materials at clinically relevant qualities and scales.

\section{EXPERIMENTAL SECTION}

Wet Chemistry Synthesis. For synthesis of $\mathrm{TiO}_{2}, \mathrm{ZrO}_{2}$, and $\mathrm{HfO}_{2}$ nanoparticles via the wet chemistry route, a surfactant free, solvent-controlled nonhydrolytic sol-gel route was applied. ${ }^{23}$ The methods of Buha et al. ${ }^{42}\left(\mathrm{HfO}_{2}\right)$, Garnweitner et al. ${ }^{39}\left(\mathrm{ZrO}_{2}\right)$, and Niederberger et al. ${ }^{51}\left(\mathrm{TiO}_{2}\right)$ were used with minor adaptions (see the Supporting Information for detailed experimental procedures). After synthesis, nanoparticles were dialyzed in ultrapure water for at least 2 days using dialysis membranes (Spectra/Por, Spectrum Labs) with an MWCO of $6-8 \mathrm{kDa}$.

FSP Synthesis. Titania, zirconia, and hafnia nanoparticles were produced by flame spray pyrolysis. ${ }^{27}$ Precursor solutions were prepared by dissolving titanium isopropoxide (TTIP, $>97 \%$, Alfa Aesar) or zirconyl 2-ethylehexanoate (in mineral spirits, $\sim 6 \% \mathrm{Zr}$,
STREM Chemicals) in xylene (>98.5\%, Sigma Aldrich) at a metal concentration of $0.16 \mathrm{M}$ followed by magnetic stirring for $30 \mathrm{~min}$. In the case of hafnia, the precursor hafnium isopropoxide isopropanol adduct (99\%, Alfa Aesar) was first dissolved in 2-ethylhexanoic acid (2-EHA, purity of $99 \%$, Sigma-Aldrich) at $120{ }^{\circ} \mathrm{C}$ under reflux overnight at a metal concentration of $0.96 \mathrm{M}$. This step was important to achieve a homogeneous nanoparticle size distribution. After cooling, the solution was diluted with five parts xylene to reach a final metal concentration of $0.16 \mathrm{M}$. The precursor solutions were fed at $3 \mathrm{~mL} \mathrm{~min}{ }^{-1}$ through a thin capillary and dispersed into fine droplets by $5 \mathrm{~L} \mathrm{~min}^{-1}$ oxygen (PanGAS, purity $>99 \%$ ) with a pressure drop of 1.5 bar. The spray flame was sustained by a ring-shaped pilot flame of premixed methane/oxygen fed at a ratio of $1.5 / 3.2 \mathrm{~L} \mathrm{~min}^{-1}$. Particles were collected on a glass microfiber filter unit (Whatman GF) connected to a gas pump (Busch Mink MM 1202 AV). After collection from the filter, the nanoparticle powder was sieved (mesh size $=250 \mu \mathrm{m})$ to remove the filter residues.

Preparation of Nanoparticle Suspensions. Wet chemistryproduced nanoparticles were used after dialysis. The nanoparticle concentration was determined by gravimetric analysis of the suspensions. FSP-synthesized particle suspensions were prepared by the addition of ultrapure water to a weighted amount of powder. All nanoparticle suspensions were vortexed and bath sonicated prior to use.

Gold Nanoparticles. Citrate-stabilized gold nanoparticles in water $\left(1 \mathrm{mg} \mathrm{mL}^{-1}\right)$ with a nominal nanoparticle size of $5 \pm 1 \mathrm{~nm}$ or $50 \pm 4 \mathrm{~nm}$ and a purity of $99.99 \%$ ("biopure") were purchased from nanoComposix (San Diego, US). Gold nanoparticles $(150 \mathrm{~nm})$ in citrate buffer were purchased from Sigma-Aldrich (product number 742058) and upconcentrated by centrifugation to reach a final concentration of $1 \mathrm{mg} \mathrm{mL}^{-1}$ before use.

Nanoparticle Characterization. Nanoparticles were characterized by X-ray diffraction (XRD), transmission electron microscopy (TEM), thermogravimetric analysis (TGA), $\mathrm{N}_{2}$-adsorption (Brunauer-Emmett-Teller (BET)), dynamic light scattering (DLS), and zeta potential measurements. Full experimental details can be found in the Supporting Information.

Cell Culture. Human fibrosarcoma HT1080 [HT1080] (ATCC CCL121) and human cervical carcinoma HeLa (ATCC CRMCCL2) cells were cultured in Minimum Essential Medium (MEM) containing $10 \%$ fetal calf serum (FCS); $1 \%$ of L-glutamine, penicillin-streptomycin-neomycin (PSN), and non-essential amino acids (NEAA); and $1 \mathrm{mM}$ sodium pyruvate. NHDF (PromoCell, Germany) were cultured in Dulbecco's Modified Eagle Medium (DMEM) with 10\% FCS and 1\% PSN. All cells were cultured at 37 ${ }^{\circ} \mathrm{C}$ in a humidified atmosphere containing $5 \% \mathrm{CO}_{2}$. The cells were subcultured after growing to $60-80 \%$ confluency.

Cytotoxicity Assay. To evaluate the cytotoxicity of nanoparticles, nanoparticle stock suspensions were prepared in ultrapure water at 5 and $1 \mathrm{mg} \mathrm{mL}^{-1}$ nanoparticle concentrations. An amount of 10,000 cells was seeded in a sterile black 96-well plate with a transparent bottom in full cell culture medium $(80 \mu \mathrm{L})$ and allowed to attach overnight. Then, to reach the final particle concentration and $100 \mu \mathrm{L}$ total volume per well, the corresponding amounts of ultrapure water (vehicle control) and freshly prepared nanoparticle suspensions were added to the cells in quadruplicate $(n=4$, technical replicates). The resulting final particle concentrations ranged from 0 to $0.1,0.25,0.5$, and $1 \mathrm{mg} \mathrm{mL}^{-1}$. The total ultrapure water content per well was $20 \%$. After nanoparticle addition, the cells were incubated for $24 \mathrm{~h}$ at $37^{\circ} \mathrm{C}$ in a standard incubator. For the cytotoxicity assay, $50 \mu \mathrm{L}$ of supernatant of each well was transferred to a new 96-well plate, and $50 \mu \mathrm{L}$ lactate dehydrogenase substrate (LDH, CytoTox 96 NonRadioactive Cytotoxicity Assay, Promega, G1780) was added. The plates were incubated in the dark for $30 \mathrm{~min}$ at room temperature, and the absorbance at $490 \mathrm{~nm}$ was measured using a Mithras LB 943 Multimode Plate Reader. To calculate LDH release, reader values were first background subtracted (mean of three background values) and subsequently normalized to the corresponding positive control.

Cell Viability Assay. To measure the viability of cells via ATP content, the left-over supernatant in each well was aspirated, and 50 
$\mu \mathrm{L}$ of fresh full cell culture medium at room temperature was added to each well. Then, CellTiter-Glo Reagent (CellTiter-Glo Luminescent Cell Viability Assay, Promega, G7571) was added (1:1 volume) and incubated for $10 \mathrm{~min}$ at room temperature on a shaker in the dark. After another 20 min of incubation in the dark, the luminescence was recorded with the plate reader. Analysis of the reader values was performed by background subtraction and normalization to the corresponding negative control (100\% viable).

Elemental Analysis Using Inductively Coupled Plasma Mass Spectrometry (ICP-MS). Prior to digestion, cell handling steps identical to an irradiation experiment (vide infra) were performed. In short, $2000 \mathrm{HT} 1080$ cells per well were seeded in $290 \mu \mathrm{L}$ cell medium in 48 -well plates. After overnight attachment, $10 \mu \mathrm{L}$ of a 0 (control), 200 , or $1000 \mathrm{ng} \mu \mathrm{L}^{-1}$ aqueous dispersion of metal oxide or gold nanoparticles was added in triplicate. After $24 \mathrm{~h}$, the nanoparticlecontaining supernatants were removed, and the cells were washed $2 \times$ with PBS, trypsinized $(80 \mu \mathrm{L})$, and covered again with culture medium. The cell number (to quantify uptake per cell) was determined by counting the cells from six pooled control wells using a hemocytometer. The remaining cell samples were harvested and stored at $-20^{\circ} \mathrm{C}$ for further analysis. Prior to ICP-MS analysis, samples were digested using the following procedure. In a $50 \mathrm{~mL}$ Falcon tube, $150 \mu \mathrm{L}$ of sample was mixed with aqua regia $(3 \mathrm{~mL}$ of $\mathrm{HCl}+1 \mathrm{~mL}$ of $\mathrm{HNO}_{3}$ ) and $1 \mathrm{~mL}$ of $\mathrm{HF}$ (only added in the case of $\mathrm{HfO}_{2}, \mathrm{ZrO}_{2}$, and $\mathrm{TiO}_{2}$ ) and allowed to react at room temperature for $3 \mathrm{~h}$ or overnight (only in the case of $\mathrm{Au}$ ). Subsequently, the visually clear samples were filled to the mark $(50 \mathrm{~mL})$ with ultrapure water. Prior to analysis, samples were diluted as necessary either in $2 \%$ $\mathrm{HNO}_{3}\left(\mathrm{HfO}_{2}, \mathrm{ZrO}_{2}\right.$, and $\mathrm{TiO}_{2}$ nanoparticles) or $1 \% \mathrm{HCl}$ (Au nanoparticles).

Elemental analysis was performed using an Agilent 7900 ICP-MS (Agilent Technologies, Santa Clara, US) instrument. To correct for non-spectral interferences (i.e., physical/matrix effects), an internal standard containing $100 \mathrm{ppb} \mathrm{Sc}, \mathrm{Ge}$, In, and Lu was mixed on-line with the sample via a t-piece at a ratio of 1:10. All elements were measured in $\mathrm{He}$ mode. Element concentrations in undiluted samples were determined using matrix-matched calibration standards (i.e., spiked with cell medium matrix at the respective concentration). An external quality control standard (IV100, Inorganic Ventures, Christiansburg, Virginia, US) was used between samples to verify the calibration and monitor measurement stability. Given the mass density differences of the metal oxides and gold $\left(\rho_{\mathrm{TiO}_{2}}=4.2 \mathrm{~g} \mathrm{~cm}^{-3}\right.$, $\rho_{\mathrm{ZrO}_{2}}=5.7 \mathrm{~g} \mathrm{~cm}^{-3}, \rho_{\mathrm{HfO}_{2}}=9.7 \mathrm{~g} \mathrm{~cm}^{-3}$, and $\left.\rho_{\mathrm{Au}}=19.3 \mathrm{~g} \mathrm{~cm}^{-3}\right)$, the mass uptake was translated into number $N$ of $5 \mathrm{~nm}$ nanoparticles per cell with $N=\frac{M_{\text {tot }}}{V_{\mathrm{NP}} \rho_{\mathrm{NP}}}$, where $V_{\mathrm{NP}}$ is the spherical nanoparticle volume with radius $r=2.5 \mathrm{~nm}, \rho_{\mathrm{NP}}$ is the density of the nanoparticle, and $M_{\text {tot }}$ is the total nanoparticle mass per cell.

Scanning Transmission Electron Microscopy (STEM) of Cells-Sample Preparation, Imaging, and Analysis. For imaging, $1.4 \times 10^{5}$ cells were seeded in $8 \mathrm{~mL}$ of culture medium in a T25 cell culture flask. After overnight attachment, $700 \mu \mathrm{L}$ of the corresponding $1 \mathrm{mg} \mathrm{mL}^{-1}$ nanoparticle suspensions was added. After a $24 \mathrm{~h}$ incubation time, the cells were washed with PBS, detached using $1 \mathrm{~mL}$ of Accutase, washed, and fixed with $2.5 \%$ glutaraldehyde in $0.1 \mathrm{M}$ cacodylate buffer for $1.5 \mathrm{~h}$. The cell pellets were stained with $2 \%$ osmium tetroxide and $1.5 \%$ potassium ferricyanide for $1 \mathrm{~h}$, gradually dehydrated using an ethanol gradient $(50,60,70,80,90$, 100,100 , and $100 \%$ ), and embedded in epoxy resin (EPON $812 \mathrm{kit}$, Sigma Aldrich), first together with ethanol (1:2 and 1:1, each for $3 \mathrm{~h}$ ) and subsequently with pure resin overnight. After another two resin changes, each for $3 \mathrm{~h}$, the resin blocks were cured in an oven at $60{ }^{\circ} \mathrm{C}$ for $72 \mathrm{~h}$, trimmed with a razor blade, and sectioned into sections with $100 \mathrm{~nm}$ thickness using an ultramicrotome. Sections were imaged using a FEI Helios and FEI NanoSEM 230 scanning electron microscope operated in transmission mode at $20 \mathrm{kV}$. The FEI Helios instrument was equipped with a high annular dark-field detector. With the FEI NanoSEM 230 instrument, a secondary electron and backscattering electron detector were used. Electron micrographs were analyzed using ImageJ (U.S. National Institutes of Health,
Bethesda, Maryland, USA). The intracellular nanoparticle agglomerates were outlined (using thresholding) and analyzed (Feret diameters: longest distance between any two points along the selection boundary; total nanoparticle agglomerate area per cell). Watershedding was used to break the assembled agglomerates.

Irradiation Setup. For irradiation of cells, a PMMA phantom was assembled in-house with a recess in its volume center designed to fit a 48-well plate (TPP, Techno Plastic Products AG, Switzerland). The phantom consisted of two equally sized slabs with dimensions of $4 \times$ $40 \times 40 \mathrm{~cm}^{3}$ each, similar to the one described by Tesei et al. ${ }^{88}$ From the center recess to one of the sides, an inlet was installed to fit a dosimetry cable with $8 \mathrm{~mm}$ diameter. A calibrated ionization chamber (N31003, PTW, Freiburg, Germany) connected to a UNIDOS ${ }^{\text {webline }}$ dosimeter (PTW, Freiburg, Germany) was used to assess the dose rate at the location of the cell plate recess before cell irradiation. This item was placed next to the cell plate during irradiation to ensure dose supply (see Figure S22 in the Supporting Information). A $12 \mathrm{~mm}$ aluminum filter was placed on top of the phantom. A $450 \mathrm{kV}$ X-ray tube source (Seifert ISOVOLT 450, GE Sensing \& Inspection Technologies $\mathrm{GmbH}$, Germany) was placed $50 \mathrm{~cm}$ above the bottom phantom slab and used at a voltage of $150 \mathrm{kV}$ and a current of $20 \mathrm{~mA}$. The dose rate at the point of the cell plate was $0.6 \mathrm{~Gy} \mathrm{~min}^{-1}$.

Cell Irradiation Experiments and Analysis. To study cell survival after irradiation, 2000 cells (HT1080, HeLa or NHDF) in $290 \mu \mathrm{L}$ of cell medium were seeded in a 48-well plate and allowed to attach overnight. On the next day, $10 \mu \mathrm{L}$ of a 0.2 or $1 \mathrm{mg} \mathrm{mL}^{-1}$ aqueous nanoparticle suspension or ultrapure water vehicle controls was added to each well in quintuplets $(n=5$, technical replicates) per irradiation condition. For the comparison study of FSP vs WetChem nanoparticles, experiments were performed in triplicate $(n=3)$ to fit on one plate. After $24 \mathrm{~h}$, the medium was removed by aspiration, and the wells were washed with PBS $(2 \times)$ and filled with $500 \mu \mathrm{L}$ of fresh medium. Thereafter, all plates were placed on ice and transported to the irradiation facilities $(45 \mathrm{~min})$. After an equilibration phase of 30 min, the cell plates were irradiated with $0,2,4,6$, and $8 \mathrm{~Gy}$, placed back on ice for another $45 \mathrm{~min}$, and placed in the culture incubator. Medium $(300 \mu \mathrm{L})$ was replaced every $2-4$ days. After $7-8$ days postirradiation, the control wells reached confluency, and a CellTiter-Glo assay was performed using $90 \mu \mathrm{L}$ of medium and $90 \mu \mathrm{L}$ of CellTiterGlo reagent, similar to the viability assay described previously. Samples were transferred from a transparent 48 -well plate into a white opaque 96-well plate for measurement in a plate reader, avoiding wellto-well crosstalk. The luminescence signals were expressed relative to the non-irradiated cells as

surviving fraction

$$
=\frac{\text { (luminescence of irradiated cells }- \text { background })_{\mathrm{w} / \text { or w/o NPs }}}{(\text { luminescence of non-irradiated cells }- \text { background })_{\mathrm{w} / \text { or } w / o ~ N P s}}
$$

The data were fit to a linear quadratic model using MATLAB (R2019b, The MathWorks, Inc., Natick, Massachusetts, United States) as

$$
\text { surviving fraction }=\mathrm{e}^{-\alpha D-\beta D^{2}}
$$

where $D$ is the exposed dose in Gy and $\alpha$ and $\beta$ are the parameters describing the cell radio-sensitivity. ${ }^{89}$ The data from the 0 Gy exposure were used to calculate the long-term viability of $24 \mathrm{~h}$ nanoparticle-treated cells compared with untreated cells.

In Vitro Dose Calculations and Size Measurements. For size measurements of nanoparticles in cell medium, aqueous nanoparticle suspensions $\left(1 \mathrm{mg} \mathrm{mL}^{-1}\right)$ were sonicated for $15 \mathrm{~min}$ and diluted in fully supplemented medium to a final concentration of $33 \mu \mathrm{g} \mathrm{mL}$ corresponding to the higher concentration used in irradiation experiments. To calculate the bottom concentration of nanoparticles in a 96-well or 48-well plate, a MATLAB code using the modified distorted grid model supplied by DeLoid et al. ${ }^{67}$ was used. Model inputs included material densities and effective agglomerate densities, material size distributions (number-weighted) as measured by DLS, media column height $(3.0 \mathrm{~mm}$ for $100 \mu \mathrm{L}$ in 96-well plates and 3.4 
$\mathrm{mm}$ for $300 \mu \mathrm{L}$ in 48-well plates), media properties such as temperature $\left(37^{\circ} \mathrm{C}\right)$, density, $\left(\rho_{\text {media }}=1.01 \mathrm{~g} \mathrm{~cm}^{-3}\right)$, and dynamic viscosity (0.00081 Pa s), and administered (initial suspension) particle concentration $\left(33 \mu \mathrm{g} \mathrm{mL}^{-3}\right.$ in the case of 48 -well). The agglomerate effective density was calculated with the sterling equation given by DeLoid et al. using a fractal dimension DF $=2.3$ and the $z$-average as hydrodynamic diameter $d_{\mathrm{H}} \cdot{ }^{90}$ With the density of the media $\rho_{\text {media }}$ and of the particles $\rho_{\mathrm{p}}$, the agglomerate effective density was calculated as

$$
\rho_{\mathrm{E}}=\left(1-\varepsilon_{\mathrm{a}}\right) \rho_{\mathrm{p}}+\varepsilon_{\mathrm{a}} \rho_{\text {media }}
$$

where $\varepsilon_{\mathrm{a}}=1-\left(\frac{d_{\mathrm{H}}}{d_{\mathrm{TEM}}}\right)^{\mathrm{DF}-3}$ is the agglomerate porosity. For the cytotoxicity dosimetry calculations (96-well), sedimentation calculations were performed using only the number-weighted hydrodynamic diameter as input and was calculated as

$$
d_{\mathrm{H}}(N)=\left\langle d_{\mathrm{H}}\right\rangle_{N}=\sum_{i} f_{N, i} d_{H, i}
$$

where $f_{N, i}$ is the number fraction of each diameter $d_{H, i}{ }^{91}$ Dosimetry calculations corresponding to the irradiation experiments (48-well) were performed using the full number-weighted size distribution as an input.

Monte Carlo Simulations. The kilovoltage photon interactions with a single nanoparticle and the total energy emission calculations were kindly reported and provided by McMahon et al. ${ }^{73}$ In short, McMahon et al. modeled the radiation-nanoparticle interactions and the resulting radial dose distributions using Geant 4 by placing individual $20 \mathrm{~nm}$ diameter nanoparticles within the center of a cube of water with $10 \mu \mathrm{m}$ sides and allowing interaction with monoenergetic $\mathrm{keV} \mathrm{X}$-rays (tuned to $20 \mathrm{keV}$ above the K-edge). The resulting total energy emission per ionizing event from a nanoparticle surface and its contribution from electrons or photons for a $\mathrm{Ti}, \mathrm{Zr}$, and $\mathrm{Hf}$ nanoparticle were calculated by summing the product of the electron or photon spectra with their energy using MATLAB, reflecting those values reported from the original paper.

$\mathrm{HfO}_{2}$ Scale-Up. The large batch of $\mathrm{HfO}_{2}$ nanopowder was produced jointly with Avantama Ltd. by providing them with the precursor recipe. $\mathrm{HfO}_{2}$ was prepared by flame spray synthesis using a precursor solution of hafnium isopropoxide (Alfa Aesar H52288) in 2ethylhexanoic acid (SAFC Q64930), and the solution was diluted

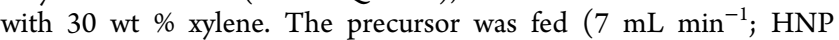
Mikrosysteme 4605, micro annular gear pump) to a spray nozzle, dispersed by oxygen $\left(13 \mathrm{~L} \mathrm{~min}^{-1}\right)$, and ignited by a premixed methane-oxygen flame $\left(\mathrm{CH}_{4}: 1.2 \mathrm{~L} \mathrm{~min}^{-1}\right.$ and $\mathrm{O}_{2}: 2.2 \mathrm{~L} \mathrm{~min}^{-1}$, both Messer AG). The off-gas was filtered through a steel mesh filter (20 micron mesh size) using a vacuum pump (Busch Mink MM 1142BV)

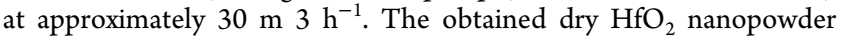
was collected from the filter mesh. The characterization, cytotoxicity, and radio-enhancement efficacies were measured according to the aforementioned procedures, with slight adaptions (dose rate of $1.2 \mathrm{~Gy}$ $\min ^{-1}$ using a $2 \mathrm{~mm}$ aluminum filter). To compare the scale-up batch to the lab batch, radio-enhancement efficiencies in HT1080 cells were assessed 4 days post-irradiation based on the above protocols.

\section{ASSOCIATED CONTENT}

\section{(s) Supporting Information}

The Supporting Information is available free of charge at https://pubs.acs.org/doi/10.1021/acs.chemmater.0c04565.

(Table S1) $d$-spacings from HRTEM pictures; (Table S2) XRD sizes; (Table S3) average hydrodynamic diameters; (Table S4) comparison of Au NP uptake into cells; (Table S5) $D_{50 \%}$ and $\mathrm{DMR}_{50 \%}$ values for all NPs; (Figure S1) XRD patterns; (Figure S2) Rietveld refinement; (Figure S3) TEM and XRD for $\mathrm{ZrO}_{2}$ as a function of reaction time; (Figure S4) TGA and DTG data; (Figure S5) DLS in medium and dosimetry calculations; (Figure S6) photographs of NP suspen- sions; (Figure S7) UV-sedimentation data; (Figure S8) TEM micrographs of air-dried NP suspensions; (Figure S9) HeLa toxicity; (Figure S10) NHDF toxicity; (Figure S11) nanoparticle cellular uptake for HeLa and NHDF cell lines; (Figure S12) STEM images of cellular uptake; (Figure S13) intracellular NP area fraction; (Figure S14) long-term toxicity HT1080; (Figure S15) long-term toxicity for all cell lines; (Figure S16) survival fractions and toxicity effect for differently sized gold nanoparticles; (Figure S17) dose enhancement efficiency of nanoparticles in HeLa cells; (Figure S18) survival fraction summary; (Figure S19) comparison between clonogenic and metabolic assay; (Figure S20) physicochemical characteristics of upscaled batch; (Figure S21) survival fraction for lab and upscaled batch; and (Figure S22) irradiation setup (PDF)

\section{AUTHOR INFORMATION}

\section{Corresponding Author}

Inge K. Herrmann - Nanoparticle Systems Engineering Laboratory, Institute of Energy and Process Engineering (IEPE), Department of Mechanical and Process Engineering (D-MAVT), ETH Zurich, 8092 Zurich, Switzerland; Particles-Biology Interactions, Department of Materials Meet Life, Swiss Federal Laboratories for Materials Science and Technology (Empa), 9014 St. Gallen, Switzerland; C orcid.org/0000-0002-3018-6796; Phone: +41 (0)58 765 7153; Email: inge.herrmann@empa.ch, ingeh@ ethz.ch

\section{Authors}

Lukas R.H. Gerken - Nanoparticle Systems Engineering Laboratory, Institute of Energy and Process Engineering (IEPE), Department of Mechanical and Process Engineering (D-MAVT), ETH Zurich, 8092 Zurich, Switzerland; Particles-Biology Interactions, Department of Materials Meet Life, Swiss Federal Laboratories for Materials Science and Technology (Empa), 9014 St. Gallen, Switzerland

Anna L. Neuer - Nanoparticle Systems Engineering Laboratory, Institute of Energy and Process Engineering (IEPE), Department of Mechanical and Process Engineering (D-MAVT), ETH Zurich, 8092 Zurich, Switzerland; Particles-Biology Interactions, Department of Materials Meet Life, Swiss Federal Laboratories for Materials Science and Technology (Empa), 9014 St. Gallen, Switzerland

Pascal M. Gschwend - Particle Technology Laboratory, Institute of Energy and Process Engineering (IEPE), Department of Mechanical and Process Engineering (DMAVT), ETH Zurich, CH-8092 Zurich, Switzerland; (1) orcid.org/0000-0002-5980-1959

Kerda Keevend - Nanoparticle Systems Engineering Laboratory, Institute of Energy and Process Engineering (IEPE), Department of Mechanical and Process Engineering (D-MAVT), ETH Zurich, 8092 Zurich, Switzerland; Particles-Biology Interactions, Department of Materials Meet Life, Swiss Federal Laboratories for Materials Science and Technology (Empa), 9014 St. Gallen, Switzerland

Alexander Gogos - Particles-Biology Interactions, Department of Materials Meet Life, Swiss Federal Laboratories for Materials Science and Technology (Empa), 9014 St. Gallen, Switzerland

Alexandre H.C. Anthis - Nanoparticle Systems Engineering Laboratory, Institute of Energy and Process Engineering 
(IEPE), Department of Mechanical and Process Engineering (D-MAVT), ETH Zurich, 8092 Zurich, Switzerland;

Particles-Biology Interactions, Department of Materials Meet Life, Swiss Federal Laboratories for Materials Science and Technology (Empa), 9014 St. Gallen, Switzerland

Leonie Aengenheister - Particles-Biology Interactions, Department of Materials Meet Life, Swiss Federal Laboratories for Materials Science and Technology (Empa), 9014 St. Gallen, Switzerland

Sotiris E. Pratsinis - Particle Technology Laboratory, Institute of Energy and Process Engineering (IEPE), Department of Mechanical and Process Engineering (D-MAVT), ETH Zurich, CH-8092 Zurich, Switzerland

Ludwig Plasswilm - Department of Radiation Oncology, Cantonal Hospital St. Gallen (KSSG), CH-9007 St. Gallen, Switzerland; University of Bern, CH-3010 Bern, Switzerland

Complete contact information is available at: https://pubs.acs.org/10.1021/acs.chemmater.0c04565

\section{Author Contributions}

L.R.H. contributed to the study design, performed experiments, analyzed data, and drafted the manuscript. A.L.N. helped with irradiation experiments and performed the clonogenic assay. P.M.G., K.K., and A.H.C.A. helped with nanoparticle synthesis and characterization. A.G. developed and performed elemental analysis protocols and acquired STEM of cells. L.A. helped with hydrofluoric acid digestion of nanoparticles. S.E.P. and L.P. actively provided input. I.K.H. conceived and supervised the study and edited the manuscript. All authors contributed to the manuscript writing and have given approval to the final version of the manuscript.

\section{Notes}

The authors declare no competing financial interest.

Parts of the schematics in Figure ${ }^{1,}$ and the TOC were created using BioRender.com.

\section{ACKNOWLEDGMENTS}

The authors acknowledge the Scientific Center for Optical and Electron Microscopy (Scope M) of ETH Zurich and the Empa Microscopy Center for support in ultramicrotome sectioning and access to their microscopes. We thank the Empa Center for X-ray Analytics for access to their facilities and Ralf Kägi and Brian Sinnet at the Swiss Federal Institute of Aquatic Science and Technology (EAWAG) for access to their HFdigestion facilities. This study was funded in parts by the Swiss National Science Foundation (Eccellenza grant no. 181290), the Swiss Cancer League (KFS-4868-08-2019), the Olga Mayenfisch Foundation and Seed Money from the EmpaCantonal Hospital St. Gallen (KSSG) program. P.M.G. and S.E.P. acknowledge funding from the Swiss National Science Foundation (grant nos. 182668 and 183298).

\section{REFERENCES}

(1) Stone, H. B.; Coleman, C. N.; Anscher, M. S.; McBride, W. H. Effects of Radiation on Normal Tissue: Consequences and Mechanisms. Lancet Oncol. 2003, 4, 529-536.

(2) Corradini, S.; Alongi, F.; Andratschke, N.; Belka, C.; Boldrini, L.; Cellini, F.; Debus, J.; Guckenberger, M.; Hörner-Rieber, J.; Lagerwaard, F. J.; Mazzola, R.; Palacios, M. A.; Philippens, M. E. P.; Raaijmakers, C. P. J.; Terhaard, C. H. J.; Valentini, V.; Niyazi, M. MR-Guidance in Clinical Reality: Current Treatment Challenges and Future Perspectives. Radiat. Oncol. 2019, 14, 92.
(3) Baskar, R.; Lee, K. A.; Yeo, R.; Yeoh, K.-W. Cancer and Radiation Therapy: Current Advances and Future Directions. Int. J. Med. Sci. 2012, 9, 193-199.

(4) Rehman, J. u.; Zahra; Ahmad, N.; Khalid, M.; Asghar, H. M. N. u.; Gilani, Z. A.; Ullah, I.; Nasar, G.; Akhtar, M. M.; Usmani, M. N. Intensity Modulated Radiation Therapy: A Review of Current Practice and Future Outlooks. J. Radiat. Res. Appl. Sci. 2018, 11, 361-367.

(5) Cui, L.; Her, S.; Borst, G. R.; Bristow, R. G.; Jaffray, D. A.; Allen, C. Radiosensitization by Gold Nanoparticles: Will They Ever Make It to the Clinic? Radiother. Oncol. 2017, 124, 344-356.

(6) Caffo, O. Radiosensitization with Chemotherapeutic Agents. Lung Cancer 2001, 34, 81-90.

(7) Mierzwa, M. L.; Nyati, M. K.; Morgan, M. A.; Lawrence, T. S. Recent Advances in Combined Modality Therapy. Oncologist 2010, $15,372-381$.

(8) Kwatra, D.; Venugopal, A.; Anant, S. Nanoparticles in Radiation Therapy: A Summary of Various Approaches to Enhance Radiosensitization in Cancer. Transl. Cancer Res. 2013, 2, 330-342.

(9) Butterworth, K. T.; McMahon, S. J.; Currell, F. J.; Prise, K. M. Physical Basis and Biological Mechanisms of Gold Nanoparticle Radiosensitization. Nanoscale 2012, 4, 4830-4838.

(10) Guerreiro, A.; Chatterton, N.; Crabb, E. M.; Golding, J. P. A Comparison of the Radiosensitisation Ability of 22 Different Element Metal Oxide Nanoparticles Using Clinical Megavoltage X-Rays. Cancer Nanotechnol. 2019, 10, 10.

(11) Vilotte, F.; Jumeau, R.; Bourhis, J. High Z Nanoparticles and Radiotherapy: A Critical View. Lancet Oncol. 2019, 20, No. e557.

(12) Howard, D.; Sebastian, S.; Le, Q. V.-C.; Thierry, B.; Kempson, I. Chemical Mechanisms of Nanoparticle Radiosensitization and Radioprotection: A Review of Structure-Function Relationships Influencing Reactive Oxygen Species. Int. J. Mol. Sci. 2020, 21, 579.

(13) Retif, P.; Pinel, S.; Toussaint, M.; Frochot, C.; Chouikrat, R.; Bastogne, T.; Barberi-Heyob, M. Nanoparticles for Radiation Therapy Enhancement: The Key Parameters. Theranostics 2015, 5, 10301044.

(14) Cooper, D. R.; Bekah, D.; Nadeau, J. L. Gold Nanoparticles and Their Alternatives for Radiation Therapy Enhancement. Front. Chem. 2014, 2, 86.

(15) Bonvalot, S.; Le Pechoux, C.; De Baere, T.; Kantor, G.; Buy, X.; Stoeckle, E.; Terrier, P.; Sargos, P.; Coindre, J. M.; Lassau, N.; Ait Sarkouh, R.; Dimitriu, M.; Borghi, E.; Levy, L.; Deutsch, E.; Soria, J.C. First-In-Human Study Testing a New Radioenhancer Using Nanoparticles (NBTXR3) Activated by Radiation Therapy in Patients with Locally Advanced Soft Tissue Sarcomas. Clin. Cancer Res. 2017, 23, 908-917.

(16) Bonvalot, S.; Rutkowski, P. L.; Thariat, J.; Carrère, S.; Ducassou, A.; Sunyach, M.-P.; Agoston, P.; Hong, A.; Mervoyer, A.; Rastrelli, M.; Moreno, V.; Li, R. K.; Tiangco, B.; Herraez, A. C.; Gronchi, A.; Mangel, L.; Sy-Ortin, T.; Hohenberger, P.; de Baère, T.; Le Cesne, A.; Helfre, S.; Saada-Bouzid, E.; Borkowska, A.; Anghel, R.; Co, A.; Gebhart, M.; Kantor, G.; Montero, A.; Loong, H. H.; Vergés, R.; Lapeire, L.; Dema, S.; Kacso, G.; Austen, L.; Moureau-Zabotto, L.; Servois, V.; Wardelmann, E.; Terrier, P.; Lazar, A. J.; Bovée, J. V. M. G.; Le Péchoux, C.; Papai, Z. NBTXR3, a First-In-Class Radioenhancer Hafnium Oxide Nanoparticle, plus Radiotherapy versus Radiotherapy Alone in Patients with Locally Advanced Soft-Tissue Sarcoma (Act.In.Sarc): A Multicentre, Phase 2-3, Randomised, Controlled Trial. Lancet Oncol 2019, 20, 1148-1159.

(17) Anselmo, A. C.; Mitragotri, S. Nanoparticles in the Clinic: An Update. Bioeng. Transl. Med. 2019, 4, No. e10143.

(18) Herrmann, I. K.; Rösslein, M. Personalized Medicine: The Enabling Role of Nanotechnology. Nanomedicine 2016, 11, 1-3.

(19) Rösslein, M.; Liptrott, N. J.; Owen, A.; Boisseau, P.; Wick, P.; Herrmann, I. K. Sound Understanding of Environmental, Health and Safety, Clinical, and Market Aspects Is Imperative to Clinical Translation of Nanomedicines. Nanotoxicology 2017, 11, 147-149.

(20) Ricketts, K.; Ahmad, R.; Beaton, L.; Cousins, B.; Critchley, K.; Davies, M.; Evans, S.; Fenuyi, I.; Gavriilidis, A.; Harmer, Q. J.; Jayne, 
D.; Jefford, M.; Loizidou, M.; Macrobert, A.; Moorcroft, S.; Naasani, I.; Ong, Z. Y.; Prise, K. M.; Rannard, S.; Richards, T.; Schettino, G.; Sharma, R. A.; Tillement, O.; Wakefield, G.; Williams, N. R.; Yaghini, E.; Royle, G. Recommendations for Clinical Translation of Nanoparticle-Enhanced Radiotherapy. Br. J. Radiol. 2018, 91, 20180325.

(21) Starsich, F. H. L.; Herrmann, I. K.; Pratsinis, S. E. Nanoparticles for Biomedicine: Coagulation During Synthesis and Applications. Annu. Rev. Chem. Biomol. Eng. 2019, 10, 155-174.

(22) Nikam, A. V.; Prasad, B. L. V.; Kulkarni, A. A. Wet Chemical Synthesis of Metal Oxide Nanoparticles: A Review. CrystEngComm 2018, 20, 5091-5107.

(23) Deshmukh, R.; Niederberger, M. Nonhydrolytic Sol-Gel Methods. In The Sol-Gel Handbook; Levy, D., Zayat, M. Eds.; Wiley-VCH Verlag GmbH \& Co. KGaA: Weinheim, Germany, 2015; pp 29-70.

(24) Mueller, R.; Jossen, R.; Pratsinis, S. E.; Watson, M.; Akhtar, M. K. Zirconia Nanoparticles Made in Spray Flames at High Production Rates. J. Am. Ceram. Soc. 2004, 87, 197-202.

(25) Mueller, R.; Mädler, L.; Pratsinis, S. E. Nanoparticle Synthesis at High Production Rates by Flame Spray Pyrolysis. Chem. Eng. Sci. 2003, 58, 1969-1976.

(26) Starsich, F. H. L.; Gschwend, P.; Sergeyev, A.; Grange, R.; Pratsinis, S. E. Deep Tissue Imaging with Highly Fluorescent NearInfrared Nanocrystals after Systematic Host Screening. Chem. Mater. 2017, 29, 8158-8166.

(27) Mädler, L.; Stark, W. J.; Pratsinis, S. E. Flame-Made Ceria Nanoparticles. J. Mater. Res. 2002, 17, 1356-1362.

(28) Teoh, W. Y.; Amal, R.; Mädler, L. Flame Spray Pyrolysis: An Enabling Technology for Nanoparticles Design and Fabrication. Nanoscale 2010, 2, 1324-1347.

(29) Mädler, L.; Kammler, H. K.; Mueller, R.; Pratsinis, S. E. Controlled Synthesis of Nanostructured Particles by Flame Spray Pyrolysis. J. Aerosol Sci. 2002, 33, 369-389.

(30) Koirala, R.; Pratsinis, S. E.; Baiker, A. Synthesis of Catalytic Materials in Flames: Opportunities and Challenges. Chem. Soc. Rev. 2016, 45, 3053-3068.

(31) Keevend, K.; Panzarasa, G.; Starsich, F. H. L.; Zeltner, M.; Spyrogianni, A.; Tsolaki, E.; Fortunato, G.; Pratsinis, S. E.; Bertazzo, S.; Herrmann, I. K. Facile MeltPEGylation of Flame-Made Luminescent $\mathrm{Tb}^{3+}$-Doped Yttrium Oxide Particles: Hemocompatibility, Cellular Uptake and Comparison to Silica. Chem. Commun. 2018, 54, 2914-2917.

(32) Eggenhuisen, T. M.; Munnik, P.; Talsma, H.; de Jongh, P. E.; de Jong, K. P. Freeze-Drying for Controlled Nanoparticle Distribution in $\mathrm{Co} / \mathrm{SiO}_{2}$ Fischer-Tropsch Catalysts. J. Catal. 2013, 297, 306-313.

(33) Wang, B.; Zhang, W.; Zhang, W.; Mujumdar, A. S.; Huang, L. Progress in Drying Technology for Nanomaterials. Drying Technol. 2005, 23, 7-32.

(34) Athanassiou, E. K.; Grass, R. N.; Stark, W. J. Chemical Aerosol Engineering as a Novel Tool for Material Science: From Oxides to Salt and Metal Nanoparticles. Aerosol Sci. Technol. 2010, 44, 161-172.

(35) Grass, R. N.; Stark, W. J. Flame Synthesis of Calcium-, Strontium-, Barium Fluoride Nanoparticles and Sodium Chloride. Chem. Commun. 2005, 13, 1767-1769.

(36) Grass, R. N.; Stark, W. J. Gas Phase Synthesis of Fcc-Cobalt Nanoparticles. J. Mater. Chem. 2006, 16, 1825-1830.

(37) Gioria, S.; Caputo, F.; Urbán, P.; Maguire, C. M.; BremerHoffmann, S.; Prina-Mello, A.; Calzolai, L.; Mehn, D. Are Existing Standard Methods Suitable for the Evaluation of Nanomedicines: Some Case Studies. Nanomedicine 2018, 13, 539-554.

(38) Garnweitner, G.; Niederberger, M. Nonaqueous and Surfactant-Free Synthesis Routes to Metal Oxide Nanoparticles. J. Am. Ceram. Soc. 2006, 89, 1801-1808.

(39) Garnweitner, G.; Goldenberg, L. M.; Sakhno, O. V.; Antonietti, M.; Niederberger, M.; Stumpe, J. Large-Scale Synthesis of Organophilic Zirconia Nanoparticles and Their Application in OrganicInorganic Nanocomposites for Efficient Volume Holography. Small 2007, 3, 1626-1632.
(40) Zhou, S.; Garnweitner, G.; Niederberger, M.; Antonietti, M. Dispersion Behavior of Zirconia Nanocrystals and Their Surface Functionalization with Vinyl Group-Containing Ligands. Langmuir 2007, 23, 9178-9187.

(41) Villa, I.; Villa, C.; Monguzzi, A.; Babin, V.; Tervoort, E.; Nikl, M.; Niederberger, M.; Torrente, Y.; Vedda, A.; Lauria, A. Demonstration of Cellular Imaging by Using Luminescent and Anti-Cytotoxic Europium-Doped Hafnia Nanocrystals. Nanoscale 2018, 10, 7933-7940.

(42) Buha, J.; Arčon, D.; Niederberger, M.; Djerdj, I. Solvothermal and Surfactant-Free Synthesis of Crystalline $\mathrm{Nb}_{2} \mathrm{O}_{5}, \mathrm{Ta}_{2} \mathrm{O}_{5}, \mathrm{HfO}_{2}$, and Co-Doped $\mathrm{HfO}_{2}$ Nanoparticles. Phys. Chem. Chem. Phys. 2010, 12, 15537-15543.

(43) Pinna, N.; Garnweitner, G.; Antonietti, M.; Niederberger, M. Non-Aqueous Synthesis of High-Purity Metal Oxide Nanopowders Using an Ether Elimination Process. Adv. Mater. 2004, 16, 21962200.

(44) Gschwend, P. M.; Krumeich, F.; Pratsinis, S. E. 110th Anniversary: Synthesis of Plasmonic Silica-Coated TiN Particles. Ind. Eng. Chem. Res. 2019, 58, 16610-16619.

(45) Stolzenburg, P.; Freytag, A.; Bigall, N. C.; Garnweitner, G. Fractal Growth of $\mathrm{ZrO}_{2}$ Nanoparticles Induced by Synthesis Conditions. CrystEngComm 2016, 18, 8396-8405.

(46) Santos, M. S.; Freitas, J. C. C.; Dalmaschio, C. J. Designed Single-Phase $\mathrm{ZrO}_{2}$ Nanocrystals Obtained by Solvothermal Syntheses. CrystEngComm 2020, 22, 1802-1811.

(47) Shimizu, T. Ferroelectricity in $\mathrm{HfO}_{2}$ and Related Ferroelectrics. J. Ceram. Soc. Jpn 2018, 126, 667-674.

(48) Scherrer, P. Bestimmung Der Inneren Struktur Und Der Größe von Kolloidteilchen Mittels Röntgenstrahlen. In Kolloidchemie Ein Lehrbuch; Zsigmondy, R. Ed.; Springer Berlin Heidelberg: Berlin, Heidelberg, 1912; pp. 387-409.

(49) Patterson, A. L. The Scherrer Formula for X-Ray Particle Size Determination. Phys. Rev. 1939, 56, 978-982.

(50) Teleki, A.; Wengeler, R.; Wengeler, L.; Nirschl, H.; Pratsinis, S. E. Distinguishing between Aggregates and Agglomerates of FlameMade $\mathrm{TiO}_{2}$ by High-Pressure Dispersion. Powder Technol. 2008, 181, 292-300.

(51) Niederberger, M.; Bartl, M. H.; Stucky, G. D. Benzyl Alcohol and Titanium Tetrachloride - A Versatile Reaction System for the Nonaqueous and Low-Temperature Preparation of Crystalline and Luminescent Titania Nanoparticles. Chem. Mater. 2002, 14, 43644370.

(52) De Roo, J.; De Keukeleere, K.; Feys, J.; Lommens, P.; Hens, Z.; Van Driessche, I. Fast, Microwave-Assisted Synthesis of Monodisperse $\mathrm{HfO}_{2}$ Nanoparticles. J. Nanopart. Res. 2013, 15, 1778.

(53) Gerken, L. R. H.; Keevend, K.; Zhang, Y.; Starsich, F. H. L.; Eberhardt, C.; Panzarasa, G.; Matter, M. T.; Wichser, A.; Boss, A.; Neels, A.; Herrmann, I. K. Lanthanide-Doped Hafnia Nanoparticles for Multimodal Theranostics: Tailoring the Physicochemical Properties and Interactions with Biological Entities. ACS Appl. Mater. Interfaces 2019, 11, 437-448.

(54) De Roo, J.; Van den Broeck, F.; De Keukeleere, K.; Martins, J. C.; Van Driessche, I.; Hens, Z. Unravelling the Surface Chemistry of Metal Oxide Nanocrystals, the Role of Acids and Bases. J. Am. Chem. Soc. 2014, 136, 9650-9657.

(55) Deshmukh, R.; Niederberger, M. Mechanistic Aspects in the Formation, Growth and Surface Functionalization of Metal Oxide Nanoparticles in Organic Solvents. Chem. - Eur. J. 2017, 23, 85428570.

(56) Kockmann, A.; Hesselbach, J.; Zellmer, S.; Kwade, A.; Garnweitner, G. Facile Surface Tailoring of Metal Oxide Nanoparticles via a Two-Step Modification Approach. RSC Adv. 2015, 5, 60993-60999.

(57) Mueller, R.; Kammler, H. K.; Wegner, K.; Pratsinis, S. E. OH Surface Density of $\mathrm{SiO}_{2}$ and $\mathrm{TiO}_{2}$ by Thermogravimetric Analysis. Langmuir 2003, 19, 160-165. 
(58) Teleki, A.; Bjelobrk, N.; Pratsinis, S. E. Continuous Surface Functionalization of Flame-Made $\mathrm{TiO}_{2}$ Nanoparticles. Langmuir 2010, 26, 5815-5822.

(59) Spyrogianni, A.; Herrmann, I. K.; Keevend, K.; Pratsinis, S. E.; Wegner, K. The Silanol Content and in Vitro Cytolytic Activity of Flame-Made Silica. J. Colloid Interface Sci. 2017, 507, 95-106.

(60) Maguire, C. M.; Rösslein, M.; Wick, P.; Prina-Mello, A. Characterisation of Particles in Solution - a Perspective on Light Scattering and Comparative Technologies. Sci. Technol. Adv. Mater. 2018, 19, 732-745.

(61) Spyrogianni, A.; Herrmann, I. K.; Lucas, M. S.; Leroux, J.-C.; Sotiriou, G. A. Quantitative Analysis of the Deposited Nanoparticle Dose on Cell Cultures by Optical Absorption Spectroscopy. Nanomedicine 2016, 11, 2483-2496.

(62) Pucci, A.; Pinna, N. Review. Non-Aqueous Sol-Gel Routes to Metal Oxide Nanocrystals under Solvothermal Conditions: Review and Case Study on Doped Group IV Metal Oxides. Z Naturforsch. B 2010, 65, 1015-1023.

(63) Feng, J.; Markwalter, C. E.; Tian, C.; Armstrong, M.; Prud'homme, R. K. Translational Formulation of Nanoparticle Therapeutics from Laboratory Discovery to Clinical Scale. J. Transl. Med. 2019, 17, 200.

(64) Kuwahara, Y.; Roudkenar, M. H.; Urushihara, Y.; Saito, Y.; Tomita, K.; Roushandeh, A. M.; Sato, T.; Kurimasa, A.; Fukumoto, M. Clinically Relevant Radioresistant Cell Line: A Simple Model to Understand Cancer Radioresistance. Med. Mol. Morphol. 2017, 50, 195-204.

(65) Marill, J.; Anesary, N. M.; Zhang, P.; Vivet, S.; Borghi, E.; Levy, L.; Pottier, A. Hafnium Oxide Nanoparticles: Toward an in Vitro Predictive Biological Effect? Radiat. Oncol. 2014, 9, 150.

(66) Moore, T. L.; Rodriguez-Lorenzo, L.; Hirsch, V.; Balog, S.; Urban, D.; Jud, C.; Rothen-Rutishauser, B.; Lattuada, M.; Petri-Fink, A. Nanoparticle Colloidal Stability in Cell Culture Media and Impact on Cellular Interactions. Chem. Soc. Rev. 2015, 44, 6287-6305.

(67) DeLoid, G. M.; Cohen, J. M.; Pyrgiotakis, G.; Demokritou, P. Preparation, Characterization, and in Vitro Dosimetry of Dispersed, Engineered Nanomaterials. Nat. Protoc. 2017, 12, 355-371.

(68) Neuer, A. L.; Gerken, L. R. H.; Keevend, K.; Gogos, A.; Herrmann, I. K. Uptake, Distribution and Radio-Enhancement Effects of Gold Nanoparticles in Tumor Microtissues. Nanoscale Adv. 2020, 2, 2992-3001

(69) Chithrani, D. B.; Jelveh, S.; Jalali, F.; van Prooijen, M.; Allen, C.; Bristow, R. G.; Hill, R. P.; Jaffray, D. A. Gold Nanoparticles as Radiation Sensitizers in Cancer Therapy. Radiat. Res. 2010, 173, 719728.

(70) Subiel, A.; Ashmore, R.; Schettino, G. Standards and Methodologies for Characterizing Radiobiological Impact of High-Z Nanoparticles. Theranostics 2016, 6, 1651-1671.

(71) McMahon, S. J.; Hyland, W. B.; Muir, M. F.; Coulter, J. A.; Jain, S.; Butterworth, K. T.; Schettino, G.; Dickson, G. R.; Hounsell, A. R.; O’Sullivan, J. M.; Prise, K. M.; Hirst, D. G.; Currell, F. J. Biological Consequences of Nanoscale Energy Deposition near Irradiated Heavy Atom Nanoparticles. Sci. Rep. 2011, 1, 18.

(72) Roeske, J. C.; Nuñez, L.; Hoggarth, M.; Labay, E.; Weichselbaum, R. R. Characterization of the Theorectical Radiation Dose Enhancement from Nanoparticles. Technol. Cancer Res. Treat 2007, 6, 395-401.

(73) McMahon, S. J.; Paganetti, H.; Prise, K. M. Optimising Element Choice for Nanoparticle Radiosensitisers. Nanoscale 2016, 8, 581589.

(74) Her, S.; Jaffray, D. A.; Allen, C. Gold Nanoparticles for Applications in Cancer Radiotherapy: Mechanisms and Recent Advancements. Adv. Drug Delivery Rev. 2017, 109, 84-101.

(75) Jain, S.; Coulter, J. A.; Hounsell, A. R.; Butterworth, K. T.; McMahon, S. J.; Hyland, W. B.; Muir, M. F.; Dickson, G. R.; Prise, K. M.; Currell, F. J.; O’Sullivan, J. M.; Hirst, D. G. Cell-Specific Radiosensitization By Gold Nanoparticles at Megavoltage Radiation Energies. Int. J. Radiat. Oncol., Biol., Phys. 2011, 79, 531-539.
(76) Perillo, B.; Di Donato, M.; Pezone, A.; Di Zazzo, E.; Giovannelli, P.; Galasso, G.; Castoria, G.; Migliaccio, A. ROS in Cancer Therapy: The Bright Side of the Moon. Exp. Mol. Med. 2020, 52, 192-203.

(77) Youkhana, E. Q.; Feltis, B.; Blencowe, A.; Geso, M. Titanium Dioxide Nanoparticles as Radiosensitisers: An In Vitro and PhantomBased Study. Int. J. Med. Sci. 2017, 14, 602-614.

(78) Joh, D. Y.; Kao, G. D.; Murty, S.; Stangl, M.; Sun, L.; Zaki, A. A.; Xu, X.; Hahn, S. M.; Tsourkas, A.; Dorsey, J. F. Theranostic Gold Nanoparticles Modified for Durable Systemic Circulation Effectively and Safely Enhance the Radiation Therapy of Human Sarcoma Cells and Tumors. Transl. Oncol. 2013, 6, 722-IN32.

(79) Khoshgard, K.; Hashemi, B.; Arbabi, A.; Rasaee, M. J.; Soleimani, M. Radiosensitization Effect of Folate-Conjugated Gold Nanoparticles on HeLa Cancer Cells under Orthovoltage Superficial Radiotherapy Techniques. Phys. Med. Biol. 2014, 59, 2249-2263.

(80) Zhang, X.-D.; Wu, D.; Shen, X.; Chen, J.; Sun, Y.-M.; Liu, P.-X.; Liang, X.-J. Size-Dependent Radiosensitization of PEG-Coated Gold Nanoparticles for Cancer Radiation Therapy. Biomaterials 2012, 33, 6408-6419.

(81) Liu, Y.; Liu, X.; Jin, X.; He, P.; Zheng, X.; Dai, Z.; Ye, F.; Zhao, T.; Chen, W.; Li, Q. The Dependence of Radiation Enhancement Effect on the Concentration of Gold Nanoparticles Exposed to Lowand High-LET Radiations. Phys Med 2015, 31, 210-218.

(82) Foroozandeh, P.; Aziz, A. A.; Mahmoudi, M. Effect of Cell Age on Uptake and Toxicity of Nanoparticles: The Overlooked Factor at the Nanobio Interface. ACS Appl. Mater. Interfaces 2019, 11, 3967239687.

(83) Wegner, K.; Pratsinis, S. E. Scale-up of Nanoparticle Synthesis in Diffusion Flame Reactors. Chem. Eng. Sci. 2003, 58, 4581-4589.

(84) Wegner, K.; Pratsinis, S. E. Gas-Phase Synthesis of Nanoparticles: Scale-up and Design of Flame Reactors. Powder Technol. 2005, 150, 117-122.

(85) Gröhn, A. J.; Pratsinis, S. E.; Sánchez-Ferrer, A.; Mezzenga, R.; Wegner, K. Scale-up of Nanoparticle Synthesis by Flame Spray Pyrolysis: The High-Temperature Particle Residence Time. Ind. Eng. Chem. Res. 2014, 53, 10734-10742.

(86) Nunes, D.; Pimentel, A.; Santos, L.; Barquinha, P.; Pereira, L.; Fortunato, E.; Martins, R. 2 - Synthesis, Design, and Morphology of Metal Oxide Nanostructures. In Metal Oxide Nanostructures; Nunes, D., Pimentel, A., Santos, L., Barquinha, P., Pereira, L., Fortunato, E., Martins, R. Eds.; Elsevier: 2019; pp. 21-57.

(87) Cheluvappa, R.; Scowen, P.; Eri, R. Ethics of Animal Research in Human Disease Remediation, Its Institutional Teaching; and Alternatives to Animal Experimentation. Pharmacol. Res. Perspect. 2017, 5, No. e00332.

(88) Tesei, A.; Sarnelli, A.; Arienti, C.; Menghi, E.; Medri, L.; Gabucci, E.; Pignatta, S.; Falconi, M.; Silvestrini, R.; Zoli, W.; D’Errico, V.; Romeo, A.; Parisi, E.; Polico, R. In Vitro Irradiation System for Radiobiological Experiments. Radiat. Oncol. 2013, 8, 257.

(89) McMahon, S. J. The Linear Quadratic Model: Usage, Interpretation and Challenges. Phys. Med. Biol. 2018, 64, No. 01 TR01.

(90) DeLoid, G.; Cohen, J. M.; Darrah, T.; Derk, R.; Rojanasakul, L.; Pyrgiotakis, G.; Wohlleben, W.; Demokritou, P. Estimating the Effective Density of Engineered Nanomaterials for in Vitro Dosimetry. Nat. Commun. 2014, 5, 3514.

(91) DeLoid, G. M.; Cohen, J. M.; Pyrgiotakis, G.; Pirela, S. V.; Pal, A.; Liu, J.; Srebric, J.; Demokritou, P. Advanced Computational Modeling for in Vitro Nanomaterial Dosimetry. Part. Fibre Toxicol. $2015,12,32$. 